OPEN ACCESS

Edited by: Yoshiaki Suzuki,

Nagoya City University, Japan

Reviewed by:

Martyn P. Mahaut-Smith,

University of Leicester,

United Kingdom

Rebecca Lewis,

University of Surrey, United Kingdom

*Correspondence:

Maria Sancho

maria.sancho-gonzalez@uvm.edu

Barry D. Kyle

barry.kyle@saskhealthauthority.ca

tThese authors have contributed equally to this work

Specialty section:

This article was submitted to

Membrane Physiology and

Membrane Biophysics,

a section of the journal

Frontiers in Physiology

Received: 30 July 2021 Accepted: 29 September 2021

Published: 21 October 2021

Citation:

Sancho M and Kyle BD (2021) The

Large-Conductance, Calcium-

Activated Potassium Channel: A Big Key Regulator of Cell Physiology.

Front. Physiol. 12:750615.

doi: 10.3389/fphys.2021.750615

\section{The Large-Conductance, Calcium- Activated Potassium Channel: A Big Key Regulator of Cell Physiology}

\author{
Maria Sancho ${ }^{1 * \dagger}$ and Barry D. Kyle ${ }^{2 * t}$ \\ ${ }^{1}$ Department of Pharmacology, University of Vermont, Burlington, VT, United States, ${ }^{2}$ Department of Pathology and \\ Laboratory Medicine, College of Medicine, University of Saskatchewan, Saskatoon, SK, Canada
}

Large-conductance $\mathrm{Ca}^{2+}$-activated $\mathrm{K}^{+}$channels facilitate the efflux of $\mathrm{K}^{+}$ions from a variety of cells and tissues following channel activation. It is now recognized that BK channels undergo a wide range of pre- and post-translational modifications that can dramatically alter their properties and function. This has downstream consequences in affecting cell and tissue excitability, and therefore, function. While finding the "silver bullet" in terms of clinical therapy has remained elusive, ongoing research is providing an impressive range of viable candidate proteins and mechanisms that associate with and modulate BK channel activity, respectively. Here, we provide the hallmarks of BK channel structure and function generally, and discuss important milestones in the efforts to further elucidate the diverse properties of BK channels in its many forms.

Keywords: BK channels, smooth muscle, nervous system, membrane potential, intracellular $\mathrm{Ca}^{2+}$

\section{INTRODUCTION}

Large-conductance $\mathrm{Ca}^{2+}$-activated $\mathrm{K}^{+}$or $\mathrm{BK}$ [Big Potassium $\left(\mathrm{K}^{+}\right)$] channels, also known as Maxi-K, Slo1 or $\mathrm{K}_{\mathrm{Ca}} 1.1$ channels, are ubiquitously expressed in a broad array of excitable and non-excitable cells including neurons/glial cells (Trimmer, 2015; Hayashi et al., 2016; Latorre et al., 2017), a variety of vascular or nonvascular smooth muscle (Nelson et al., 1995; Nelson and Quayle, 1995; Brenner et al., 2005; Herrera et al., 2005; Hu and Zhang, 2012; Kyle et al., 2013; Krishnamoorthy-Natarajan and Koide, 2016; Dopico et al., 2018), skeletal muscle (Pallotta et al., 1981), neuroendocrine cells (Solaro et al., 1995) and, epithelial cells (Manzanares et al., 2011; Yang et al., 2017). These channels are characterized by exhibiting a high $\mathrm{K}^{+}$selectivity, a large single channel conductance of $200-300 \mathrm{pS}(\sim 10-20$-fold greater that other $\mathrm{K}^{+}$channels), and an exquisite ability to be dually activated by two distinct physiological stimuli: membrane depolarization and local increases in intracellular $\mathrm{Ca}^{2+}$ (Marty, 1981; Pallotta et al., 1981; Barrett et al., 1982; Latorre et al., 1982, 1989; Marty, 1989). Given their unusual and very impressive large unitary conductance, the stimulation of BK channels leads to a rapid efflux of $\mathrm{K}^{+}$, which results in membrane hyperpolarization. This capability therefore confers an important physiological mechanism to modulate membrane excitability and intracellular $\mathrm{Ca}^{2+}$ homeostasis. Thus, BK channels are key players in a plethora of physiological processes such as smooth muscle contraction (Brayden and Nelson, 1992; Nelson et al., 1995; Pérez et al., 1999; Wellman and Nelson, 2003), neuronal signaling (Robitaille and Charlton, 1992; Hu et al., 2001; Raffaeli et al., 2004; Wang, 2008), hormone secretion (Braun et al., 2008) and audition (Miranda-Rottmann et al., 2010). In the brain, 
astrocyte endfeet express functional BK channels with the ability to sense astrocytic $\mathrm{Ca}^{2+}$. This in turn signals to neighboring arteriolar smooth muscle cells by the focal release of $\mathrm{K}^{+}$into the perivascular space, thus playing an essential role in neurovascular coupling and the regulation of brain blood flow (Filosa et al., 2006).

In harmony with these vital physiological functions, both malfunctioning and abnormal expression (loss or gain of function) of $\mathrm{BK}$ channels can have detrimental consequences on the excitability of neuronal or vascular networks (N'Gouemo, 2014; Contet et al., 2016). Thus, BK channels are now recognized to play a role in numerous pathophysiological conditions including seizures and epilepsy (Du et al., 2005; N'Gouemo, 2011), movement disorders (Du et al., 2005; Imlach et al., 2008), autism and mental retardation (Laumonnier et al., 2006), cerebral ischemia and hypoxia (Gribkoff et al., 2001; Kumar, 2007; Liao et al., 2010; Tao et al., 2015), hypertension (Brenner et al., 2000; Pabbidi and Roman, 2017), obesity (Jiao et al., 2011) and diabetes mellitus (Gutterman and Durand, 2014). In this review, we provide an overview of the basic biophysical features, including structural, functional and pharmacological properties of mammalian BK channels, with a particular focus on their pathological implication as well as their potential as molecular targets for the development of innovative and promising therapeutic strategies in the nervous and cardiovascular systems.

\section{BIOPHYSICAL FEATURES OF LARGE- CONDUCTANCE $\mathrm{Ca}^{2+}$-ACTIVATED $\mathrm{K}^{+}$ CHANNELS}

\section{The Structure of BK Channels}

As members of the TM6 voltage-gated ion channel superfamily, BK channels share partial topology with voltage-gated $\mathrm{K}^{+}\left(\mathrm{K}_{\mathrm{v}}\right)$ channels and, constitute tetramers of the pore-forming $\alpha$-subunits or Slo1 proteins, encoded by a single gene, termed Slo1 or KCNMA1 in mammals. The Slo1 gene undergoes extensive alternative splicing (Tseng-Crank et al., 1994; Navaratnam et al., 1997), giving rise to a high degree of functional diversity in BK channels. It was firstly identified in the Slowpoke mutant of Drosophila melanogaster. This mutant exhibited abnormal locomotor patterns and obvious impaired flight ability due to a deficiency in a $\mathrm{Ca}^{2+}$-activated conductance (Elkins et al., 1986; Atkinson et al., 1991). Each $\alpha$-subunit, containing about 1,200 amino acids, is comprised of 7 membrane-spanning domains (i.e., S0-S6; 330 amino acids) (Wallner et al., 1996) with $\mathrm{S} 4$ considered as a conserved positively charged domain that acts as a well-defined voltage sensor as seen in $\mathrm{K}_{\mathrm{v}}$ channels (Liman et al., 1991; Lopez et al., 1991; Logothetis et al., 1993; Seoh et al., 1996). The pore-gated domain is constituted by S5 and S6 transmembrane segments; it forms the center of the $\mathrm{BK}$ channel and acts as a $\mathrm{K}^{+}$selective filter. Additionally, the $\alpha$-subunit contains an extensive ( $\sim 840$ amino acids) C-terminal cytosolic region with four additional hydrophobic segments (S7-S10) containing two non-identical domains (RCK1 and RCK2), serving as regulators for $\mathrm{K}^{+}$conductance. Each of the RCK domains contain a high-affinity binding $\mathrm{Ca}^{2+}$ site and multiple regulatory domains for a variety of ligands (Jiang et al., 2002; Xia et al., 2002; Sweet and Cox, 2009) or divalent cations including $\mathrm{Mg}^{2+}$ (Shi et al., 2002; Xia et al., 2002; Yang et al., 2008; Figure 1). Interestingly, the "gating ring" of the tetramer is constituted by these four RCK1-RCK2 arrangements (Tao et al., 2017). While $\mathrm{Ca}^{2+}$ ions are powerful promoters of BK channel open probability, other $\mathrm{Ca}^{2+}$-activated $\mathrm{K}^{+}$channel species, activated by lower intracellular $\mathrm{Ca}^{2+}$ concentrations [i.e., small (SK) or intermediate (IK) $\mathrm{K}^{+}$channels], display a completely dissimilar channel gating mechanism. This process requires calmodulin (CaM), a small but highly conserved $\mathrm{Ca}^{2+}$ modulating protein, to bind with $\mathrm{Ca}^{2+}$ ions (Fanger et al., 1999; Adelman, 2016). Specifically, four CaM molecules attach to the channel tetramer causing a conformational change of the S4-S5 linker that promotes the opening of the channel pore in a cooperative manner with high $\mathrm{Ca}^{2+}$ sensitivity (Xia et al., 1998).

The structural features of the $\alpha$-subunit confer unique biophysical properties to the channel including ion permeation,

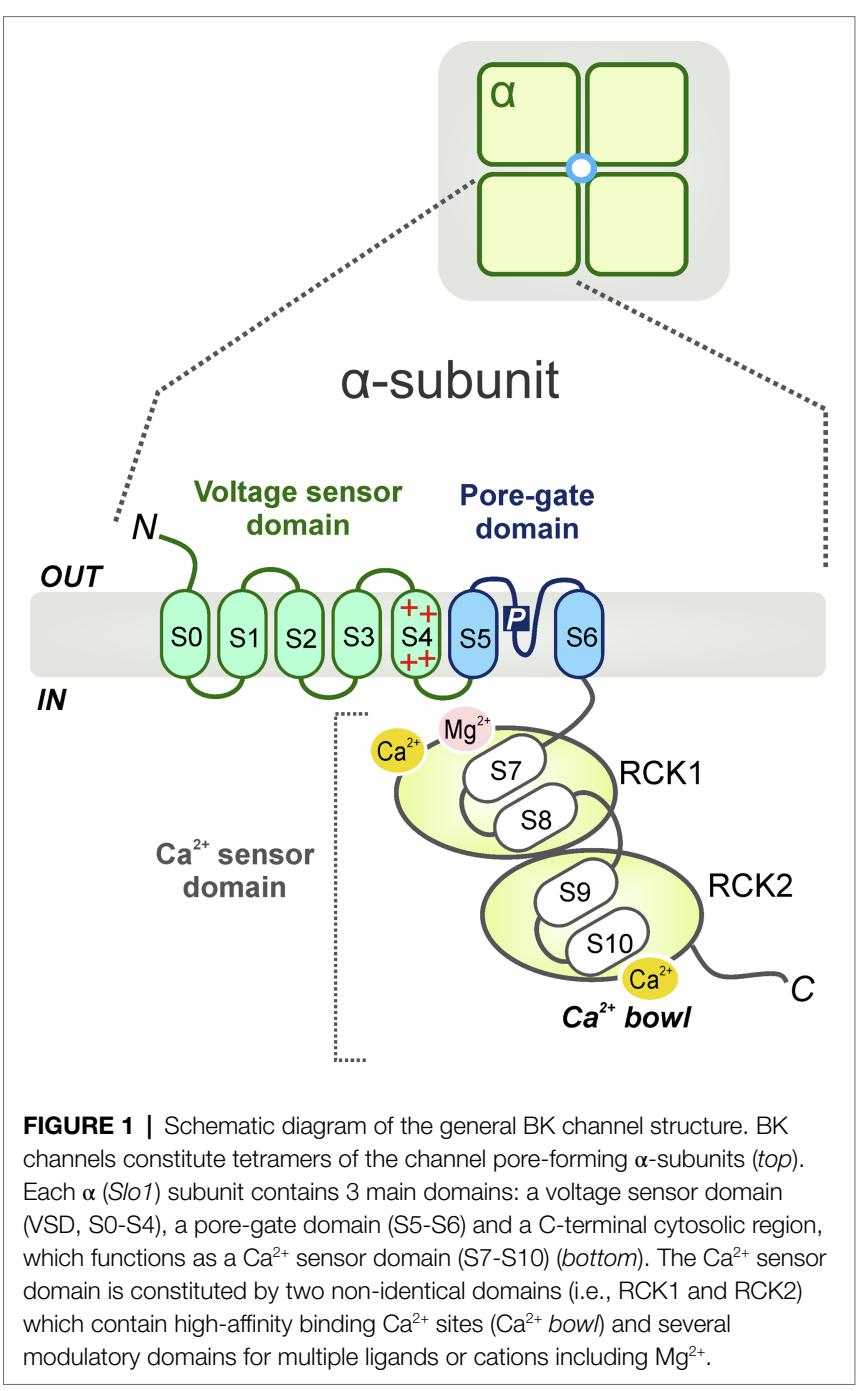


gating and regulation by diverse ligands and intracellular molecules and ions. Notably, the pharmacology and functional features of BK channels, such as their sensitivity to voltage and intracellular $\mathrm{Ca}^{2+}$, are prominently impacted by their association with auxiliary and non-pore-forming modulatory $\beta\left(\beta_{1-4}\right)$ (Brenner et al., 2000; Yan and Aldrich, 2010), $\gamma\left(\gamma_{1-4}\right)$ (Yan and Aldrich, 2010, 2012), and LINGO1 subunits (Dudem et al., 2020). Most importantly, the co-assembling with diverse auxiliary subunits gives rise to the existence of distinct BK channel phenotypes with varied functionality, thus increasing channel heterogeneity. Specifically, the identity of the regulatory subunits that associate with BK channels dictates important electrophysiological and kinetic features of the channel including the voltage range of activation, inactivation or deactivation, single-channel current rectification characteristics, as well as pharmacological sensitivity to different channel blockers (Gonzalez-Perez and Lingle, 2019). In this aspect, recent literature has centered on $\mathrm{BK}$ channel gating modulation by these auxiliary subunits (Contreras et al., 2012; Torres et al., 2014; Zhang and Yan, 2014), with a particular emphasis on the unique role of the $\beta-1$ subunit in BK channels in smooth muscle and kidney (Krishnamoorthy-Natarajan and Koide, 2016; Latorre et al., 2017).

The complexity of BK channel function reflects the intricacy of its protein structure. In the last decade, several studies employing electron cryomicroscopy (cryo-EM) and X-ray crystallographic analysis have begun to provide key structural and biophysical insights into the $\mathrm{BK}$ channel gating (Wang and Sigworth, 2009; Lee and Cui, 2010; Yuan et al., 2010; Hite et al., 2017). However, a complete knowledge of BK channel structure is needed to provide not only a more informed understanding of its biological role(s), but also refined targeting in the practical search for novel drugs and compounds to treat diverse BK-associated pathologies while mitigating potential side effects. Importantly, more extensive crystallographic analyses of the diverse auxiliary subunits may add new dimensions to BK channel modulation and add potential targeting options to the channel in a more tissue- or cell-specific manner. This section will review the organization and structural basis for gating the BK channel as they are currently understood.

\section{The Voltage Sensor and Activation of BK Channels by Membrane Voltage}

One of the most defining hallmarks of BK channels is their mechanism of activation by membrane depolarization and changes in cytosolic $\mathrm{Ca}^{2+}$ levels in a synergetic fashion. This idea is supported by various allosteric models revealing that $\mathrm{BK}$ channels can open the pore gates and allow $\mathrm{K}^{+}$efflux in the absence of voltage sensor activation and $\mathrm{Ca}^{2+}$ binding with an intrinsic open probability $\left(\mathrm{P}_{\mathrm{o}}\right)$ of $\sim 10^{-7}$. (Horrigan et al., 1999). These models further demonstrated that in the practical absence of intracellular $\mathrm{Ca}^{2+}\left[\left(\mathrm{Ca}^{2+}\right)<1 \mathrm{nM}\right]$, membrane depolarization is sufficient to reduce the free energy necessary to maximally stimulate voltage-dependent macroscopic ionic currents through BK channels (Cui et al., 1997; Horrigan et al., 1999; Horrigan and Aldrich, 1999). In this sense, a depolarization greater than $+200 \mathrm{mV}$ was necessary to promote channel opening at $\sim 0.5 \mathrm{nM}$ intracellular $\mathrm{Ca}^{2+}$. This $\mathrm{Ca}^{2+}$-independent activation of the $\mathrm{BK}$ channel is reinforced by the fact that the time constant of current stimulation was three orders of magnitude faster than the averaged diffusion-limited time it would take $\mathrm{Ca}^{2+}$ to bind the channel during depolarization (Cui et al., 1997). These latter observations combined with their structural similarity to $\mathrm{K}_{\mathrm{v}}$ channels, suggest that BK channels possess a virtuously voltage-dependent mechanism of gating conferred by the existence of an intrinsic voltage sensor domain (VSD, S0-S4).

Structurally, the VSD in BK channels resembles the voltagesensing apparatus of $\mathrm{K}_{\mathrm{v}}$ channels but with an additional $\mathrm{N}$-terminal transmembrane segment (S0), which exhibits similar voltage dependence to the positively charged S4 domain [i.e., contains three Arginine [Arg] residues] and is important for $\beta$-subunit modulation (Meera et al., 1997). Diverse electrophysiological assays have demonstrated that the S0 helix is remarkably close to the extracellular domains of S3 and S4 (Liu et al., 2008) and functionally modulates the transition between the resting and the fully active state of the VSD upon membrane depolarization (Koval et al., 2007).

In terms of functionality, the voltage sensor of BK channels differs from that of $\mathrm{K}_{\mathrm{v}}$ channels in two main aspects. First, the number of voltage-sensing charges (gating charge) of $\mathrm{BK}$ channels - measured as the depolarization-induced movement of the VSD - are smaller compared to $\mathrm{Kv}$ channels (0.6e vs. $\sim 12-13 e$ effective gating charges in $\mathrm{BK}$ vs. $\mathrm{K}_{\mathrm{v}}$ channels), suggesting the requirement of more membrane depolarization to move the VSD of BK channels into the fully activated state. This relatively weak voltage dependence allows BK channels to function throughout a wide range of membrane potentials. Second, while in $\mathrm{K}_{\mathrm{v}}$ channels each of the first four most extracellular charges (Arg residues) of S4 is voltage sensing and contributes to the gating currents (Bezanilla, 2008), only one Arginine residue influences the actual BK channel gating. This observation suggests the existence of additional charged residues outside of S4 with essential contributions to the total amount of gating charges (Ma et al., 2006). Specifically, two supplementary voltage-sensing charged residues (accounting for at least $50 \%$ of gating currents) have been described in the BK S2 segment, and the S3 domain carries an additional residue, also involved in charge-related movements of the gating current. Given the various remarkable dissimilarities, it is possible that the $\mathrm{BK}$ channels perform a similar but unique mode of structural rearrangement of the VSD during channel gating (Ma et al., 2006). Further studies using the voltageclamp fluorometry technique have tracked the relative motions of the BK channel VSD domain upon membrane depolarization, providing a fundamental structural basis to gain a better understanding of the voltage-sensing operation of BK channels (Pantazis et al., 2010; Pantazis and Olcese, 2012).

\section{The Calcium Sensor and Calcium Sensitivity of BK Channels}

$\mathrm{Ca}^{2+}$ binding promotes $\mathrm{BK}$ channel opening independently of the voltage-sensing apparatus of the channel. This evidence 
was elegantly demonstrated by classic electrophysiology studies in which the steady-state open probability of BK channels increased as the intracellular $\mathrm{Ca}^{2+}$ concentration was elevated (from $<10 \mathrm{nM}$ to $1,000 \mu \mathrm{M}$ ) at a fixed transmembrane voltage (Markwardt and Isenberg, 1992) or at very negative voltages (less than $-80 \mathrm{mV}$ ) where voltage sensors are largely in resting states (Horrigan and Aldrich, 2002).

Physiologically, BK channel activity can be enhanced by elevating cytosolic $\mathrm{Ca}^{2+}$ concentrations, since $\mathrm{Ca}^{2+}$ binds with high affinity to the cytoplasmic domain(s). Several divalent cations (including $\mathrm{Ca}^{2+}$ ) are sensed by the so-called "gating ring," a large tetrameric arrangement made up of two different regulators of conductance of potassium (i.e., RCK1 and RCK2) domains. As stated above, each RCK domain possesses a highaffinity $\mathrm{Ca}^{2+}$ site (commonly known as the " $\mathrm{Ca}^{2+}$ bowl") where $3 \mathrm{Ca}^{2+}$ ions can bind (i.e., $24 \mathrm{Ca}^{2+}$ ions/channel), leading to a change in the conformation of the gating ring and switching into a conducting state (Pau et al., 2011). In addition, BK channel subunits contain at least a low-affinity site for $\mathrm{Ca}^{2+}$ and $\mathrm{Mg}^{2+}$ at the interface between the voltage sensor and the RCK1 domain (Zhang et al., 2001). Interestingly, when $\mathrm{Mg}^{2+}$ ions bind to this site, a charged residue in the S4 domain is repelled, therefore enabling the active configuration of the VSD, and indirectly promoting BK channel opening (Hu et al., 2003).

In addition to $\mathrm{Ca}^{2+}$ and $\mathrm{Mg}^{2+}$, RCK domains can sense other divalent cations such as $\mathrm{Cd}^{2+}, \mathrm{Ba}^{2+}, \mathrm{Mn}^{2+}, \mathrm{Co}^{2+}$, or $\mathrm{Ni}^{2+}$, with relatively low selectivity to that for $\mathrm{Ca}^{2+}$ (Xia et al., 2002: Zeng et al., 2005). Furthermore, an additional low-affinity-Ca ${ }^{2+}$ binding site for the ions with smaller radii (i.e., $\mathrm{Mn}^{2+}, \mathrm{Co}^{2+}$, $\mathrm{Mg}^{2+}$ and $\mathrm{Ni}^{2+}$ ) has been noted by Zeng et al. (2005).

The binding of intracellular $\mathrm{Ca}^{2+}$ (or other divalent cations) promotes a leftward shift of the steady-state open probability of BK channels, a process which is correlated with a slowing deactivation of the channel (Barrett et al., 1982). Electrophysiological studies combined with $\mathrm{Ca}^{2+}$-dependent kinetic analysis of the BK channel have determined that its $\mathrm{Ca}^{2+}$ affinity resides mainly in the low micromolar range (i.e., 1-10 $\mathrm{M}$ ) (Cox et al., 1997; Contreras et al., 2013), and can be modulated by a variety of ligands and metabolic states (Xia et al., 2002). The spatial interaction between BK channels and voltage-gated calcium channels (VGCC) appears to be critical for promoting BK channel activation at low membrane voltages. In fact, several studies have shown colocalization or the existence of BK-VGCC macromolecular complexes which mediate rapid and focalized $\mathrm{Ca}^{2+}$-activated $\mathrm{K}^{+}$signaling in neurons (Berkefeld et al., 2006).

In vascular smooth muscle, BK channels are associated with elevations in intracellular $\mathrm{Ca}^{2+}$ concentrations by behaving as a negative feedback mechanism to oppose the nearly always partially constricted state of resistance arteries (i.e., vascular tone) exhibited under physiological conditions (Figure 2). In particular, highly localized intracellular $\mathrm{Ca}^{2+}$ transients, known as "Ca ${ }^{2+}$ sparks," are triggered by the concurrent opening of a number of ryanodine-sensitive $\mathrm{Ca}^{2+}$ release (RyR) channels in the sarcoplasmic reticulum. This in turn elevates local $\mathrm{Ca}^{2+}$ levels $(10-100 \mu \mathrm{M})$ that activates multiple adjacent BK channels, leading to transient macroscopic currents referred to as spontaneous transient outward currents (i.e., "STOCs") and subsequent membrane hyperpolarization by closing VGCC and decreasing intracellular $\mathrm{Ca}^{2+}$ concentrations (Nelson et al., 1995; Bonev et al., 1997; Porter et al., 1998). Notably, simultaneous recordings of $\mathrm{Ca}^{2+}$ sparks and cell membrane potential revealed that $\mathrm{Ca}^{2+}$ sparks elicited up to $\sim 20 \mathrm{mV}$ hyperpolarization of arterial smooth muscle through the activation of BK channels (Ganitkevich and Isenberg, 1990). Accordingly, blockade of either $\mathrm{Ca}^{2+}$ sparks or $\mathrm{BK}$ channels depolarized pressurized cerebral arteries causing an increase in intracellular $\mathrm{Ca}^{2+}$ levels and subsequent vasoconstriction (Nelson et al., 1995; Knot et al., 1998; Porter et al., 1998). These relevant studies provided solid evidence for $\mathrm{Ca}^{2+}$ sparks functioning as essential regulators of the vascular tone through the activation of BK channels.

\section{PHARMACOLOGY OF BK CHANNELS}

BK channel activity can be modulated by numerous endogenous mediators, intracellular signaling proteins, peptide toxins, smallmolecule blockers, and/or endogenous or synthetic openers (Figure 3). This section reviews these regulating molecules and their potential in delineating the physiological and pathophysiological implications for BK channels.

\section{Regulation by Signaling Molecules or Endogenous Mediators}

Physiologically, BK channel activity may be regulated via a wide variety of intracellular signaling molecules that bind to the cytoplasmic domain of the channel, including $\mathrm{Mg}^{2+}$, which depending on its concentration, can exert opposing effects in the activity of BK channels. While at physiological concentrations $(0.5 \mathrm{mM})$ and in the presence of relatively low $\mathrm{Ca}^{2+}$ levels, $\mathrm{Mg}^{2+}$ shifts the voltage-dependent opening of BK channels toward more hyperpolarized voltages, higher levels of this divalent cation (1-4 mM) diminish BK channel unitary amplitude in a voltage-dependent manner (Zamoyski et al., 1989; Ferguson, 1991; McLarnon and Sawyer, 1993; Zhang et al., 1995, 2001; Morales et al., 1996; Shi and Cui, 2001; Shi et al., 2002; Xia et al., 2002).

There is also a growing literature on BK channel activity modulation by intracellular protons (Schubert et al., 2001; Schubert and Nelson, 2001; Avdonin et al., 2003; Brelidze and Magleby, 2004; Raingo et al., 2005; Park et al., 2007; Hou et al., 2009). Electrophysiological analysis using native smooth muscle cells from rat tail arteries revealed that while $\mathrm{pH}$ fluctuations (ranging 7.0-7.8) were unable to alter single-channel conductance or voltage-dependence of activation, the amplitude of intact BK channel currents were markedly decreased when lowering the $\mathrm{pH}$ from 7.2-6.8 (Schubert et al., 2001). In contrast, Dabertrand et al. (2012) elegantly demonstrated that brain acidosis induces the transformation of $\mathrm{Ca}^{2+}$ waves into $\mathrm{Ca}^{2+}$ sparks, leading to the activation of BK channels and subsequent dilation of brain parenchymal arterioles. The latter effect is due to the inherent ability of protons to bind to $\mathrm{Ca}^{2+}$ sensing residues located at the $\mathrm{C}$-terminus of the BK channel. Specifically, 


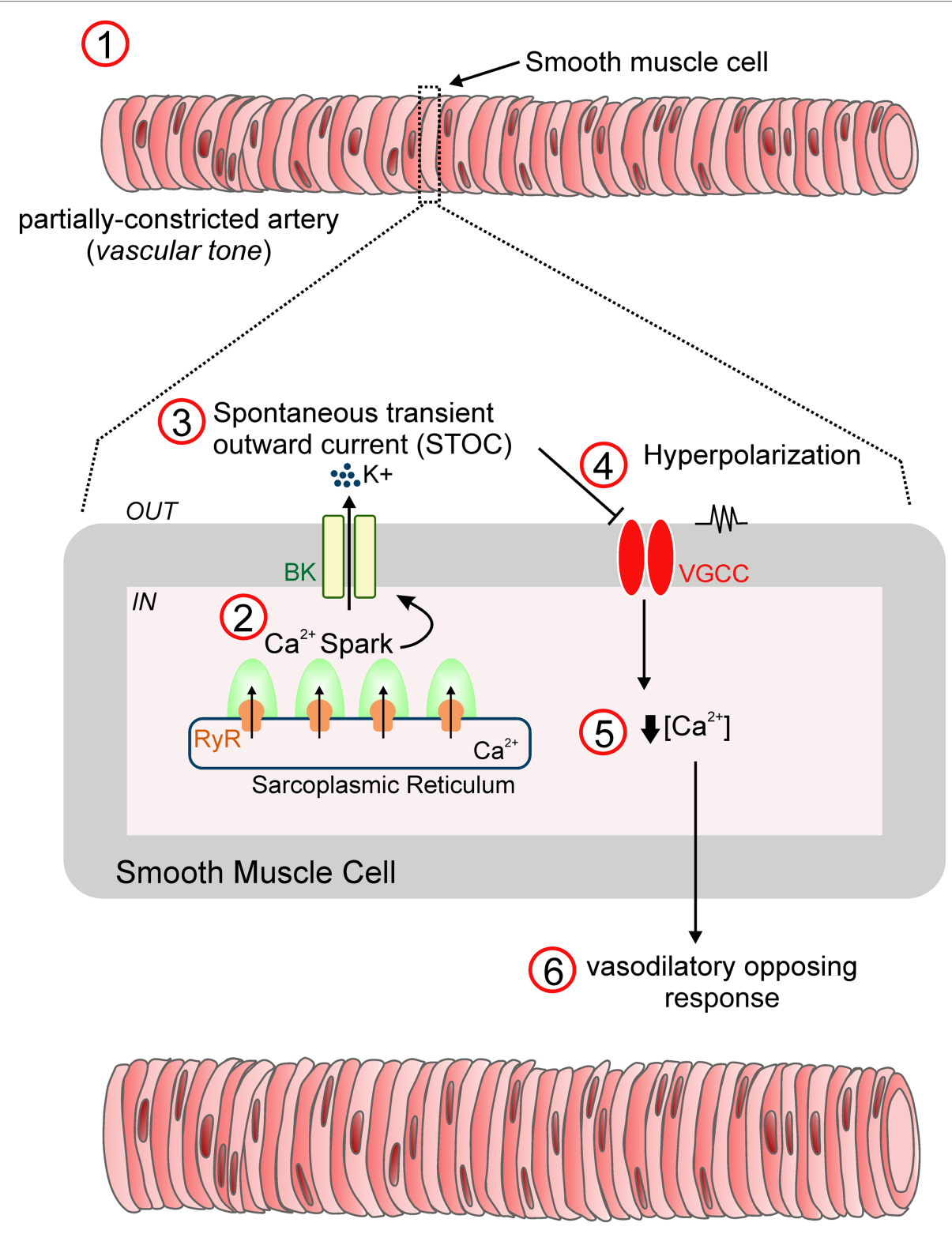

FIGURE 2 | STOC-mediated vasodilation mechanism. In vascular smooth muscle, BK channels are key drivers of negative feedback control via the regulation of membrane excitability, an essential mechanism that prevents excessive constriction of resistance arteries (1). Specifically, transient activation of ryanodine receptors (RyR) residing in the sarcoplasmic reticulum leads to the generation of " $\mathrm{Ca}^{2+}$ sparks" (2). Single sparks increase the $\mathrm{Ca}^{2+}$ concentration in the vicinity of membrane BK channels, provoking their opening and the subsequent development of macroscopic $\mathrm{K}^{+}$currents referred to as "Spontaneous transient outward currents (STOCs)" (3). This in turn, contributes to membrane hyperpolarization by reducing the voltage-gated $\mathrm{Ca}^{2+}$ channel (VGCC) open probability (4), and a relative reduction in the intracellular $\mathrm{Ca}^{2+}$ levels (5). As a result, the resistance artery develops a dilatory response (6), a vital feedback mechanism to optimize arterial tone development (Nelson et al., 1995).

intracellular protons target three residues [i.e., two Histidines (His) and, one Aspartate (Asp)] residing within the RCK1 domain of the BK channel (Avdonin et al., 2003).

Oxidative stress causes contrasting effects on BK channel function. Diverse studies in vascular smooth muscle have shown an increase in BK channel activity by oxidizing agents such as 5'5-dithiobis (2-nitrobenzonic acid, DNTB; Thuringer and Findlay, 1997), nicotinamide adenine dinucleotide (NAD) and glutathione sulfide (Lee et al., 1994), while other redox derivatives including dithiothreitol (DTT), $\beta$-mercaptoethanol, NADH or reduced glutathione (GSH) diminished BK currents (Thuringer and Findlay, 1997). Peroxynitrite, an oxidant produced by the near diffusion-controlled reaction between NO and superoxide ion, decreases BK channel open probability in cerebrovascular and coronary smooth muscle, leading to vessel constriction (Brzezinska et al., 2000; Liu et al., 2002). Furthermore, the inhibitory effect of peroxynitrite was reversible and thioldependent as the BK current amplitude was rescued by the 


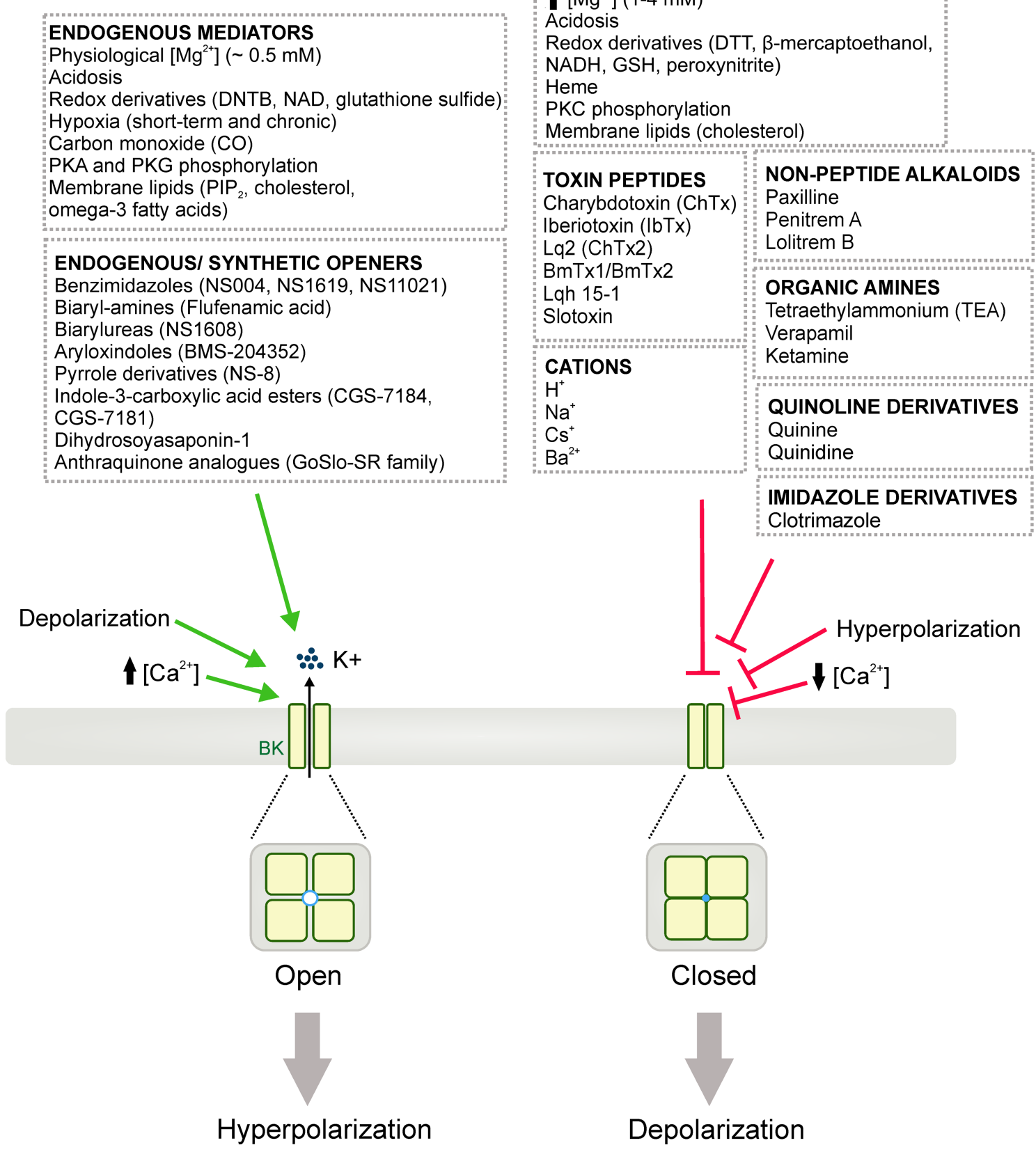

FIGURE 3 | Diagrammatic summary of the pharmacology of BK channels. BK channels can be activated (i.e., opened) or blocked (i.e., closed or inhibited) leading to cell membrane hyperpolarization and depolarization, respectively. Diverse endogenous mediators, redox derivatives and, signaling proteins are able to either potentiate or inhibit BK channel activity. Numerous BK channel inhibitors/blockers have been also reported, including: toxin peptides from scorpion venoms, nonpeptide alkaloids, organic amines, quinolone and imidazole derivatives. Additionally, an extensive list of cations including $\mathrm{H}^{+}, \mathrm{Na}^{2+}, \mathrm{Cs}^{+}$and $\mathrm{Ba}^{2+}$ are shown to influence BK channel activity. Similarly, endogenous and synthetic openers have been widely studied as experimental tools and potential therapeutic approaches for different vascular or neurological disorders involving BK channels.

antioxidant GSH. Acute or chronic deprivation of adequate oxygen supply (i.e., hypoxia) also influences the activity of BK channels with downstream effects on vascular tone. During short-term hypoxia, the brain vasculature dilates to increase cerebral blood flow, a mechanism of autoregulation which is thought to be partially mediated by BK channels (Gebremedhin et al., 1994). Similarly, Tao et al. (2015) demonstrated a stimulatory effect of chronic hypoxia on BK channel activity by increasing channel affinity for $\mathrm{Ca}^{2+}$ and shifting voltage channel activation to more hyperpolarized membrane potentials. 
Heme, an essential cofactor involved in the redox-sensitive reaction of hemoproteins, directly binds to BK channel either in its oxidized or reduced state and drastically inhibits its activity (Tang et al., 2003). Further studies demonstrated that heme can impact the effect of allosteric activators of BK channels by possibly altering the architecture of the channel gating ring and thus, the voltage-sensing apparatus and the intrinsic stability of the open state of the channel (Horrigan et al., 2005). These findings suggest heme can function as a potent brake of BK channel activity, and it represents a clinically relevant agent with a potential cytoprotective role during conditions of "heme stress" or "excess of heme" such as trauma, ischemia or hypoxia (Gribkoff et al., 2001; Doré, 2002; Xu et al., 2002).

Carbon monoxide (CO) induces cerebral artery vasodilation through the activation of smooth muscle $\mathrm{BK}$ channels and thus increasing $\mathrm{Ca}^{2+}$ spark/STOC coupling. Specifically, CO reverses heme-induced $\mathrm{BK}$ channel inhibition by impairing the interaction between heme and its conserved binding domain (Jaggar et al., 2005). More detailed electrophysiology studies using inside-out, excised patch-clamp revealed that $\mathrm{CO}$-induced BK channel activation is independent of the oxidation state of the gating ring of the channel and partly dependent on physiological levels of intracellular $\mathrm{Ca}^{2+}$ (Williams et al., 2008).

The action of various kinases including cAMP-dependent protein kinase (PKA), cGMP-dependent (PKG), and PKC directly regulates the apparent $\mathrm{Ca}^{2+}$ - and/or voltage-sensitivity of $\mathrm{BK}$ channels, and thus, their physiological activity (Schubert and Nelson, 2001). Furthermore, BK channels are shown to contribute to the actions of many endogenous vasodilators [i.e., calcitoningene-related peptide (CGRP) or nitric oxide (NO)] that signal via adenylyl or guanylyl cyclase resulting in the elevation of cAMP or cGMP intracellular levels (Robertson et al., 1993; Miyoshi and Nakaya, 1995; Peng et al., 1996). In this context, several studies demonstrated the stimulatory influence of PKA and PKG phosphorylation on the kinetics of the BK channel, but not the conductance per se, causing a leftward voltage shift and increasing the open probability of the channel (Robertson et al., 1993; Minami et al., 1993a,b). In contrast, PKC phosphorylation directly attenuates BK currents in arterial smooth muscle (Schubert et al., 1999; Taguchi et al., 2000).

The activity of BK channels can be further modulated by the action of several membrane lipids (see Dopico and Bukiya, 2014 for a comprehensive review) including the minor but ubiquitous phospholipid component of cell membranes, phosphatidylinositol 4,5-bisphosphate $\left(\mathrm{PIP}_{2}\right)$, the fundamental membrane lipid component cholesterol (Vaithianathan et al., 2008; Dopico et al., 2012; Tang et al., 2014; Tian et al., 2015; Dopico and Bukiya, 2017) and omega-3 fatty acids (Hoshi et al., 2013a,b). PIP $_{2}$ directly stimulates vascular smooth muscle BK channels, contributing to vascular tone and blood flow control. Specifically, its negatively charged inositol head group interacts with a conserved motif in the cytoplasmic domain of the channel $\alpha$ subunit. The stimulatory effect of $\mathrm{PIP}_{2}$ is conferred by the accessory subunits that comprise the channel, potentiated by $\beta_{1}$, which is abundantly expressed in smooth muscle, but not by $\beta_{4}$ subunits. Consequently, pharmacological manipulation of endogenous $\mathrm{PIP}_{2}$ levels results in endothelium-independent dilation of cerebral resistance arteries, an effect that is blunted by selective BK channel blockers (Vaithianathan et al., 2008). Similarly, omega-3 fatty acids are known to potentiate $\mathrm{BK}$ channel activity in coronary artery smooth muscle and cause dilation of isolated coronary arteries (Lai et al., 2009; Wang et al., 2011; Hoshi et al., 2013a,b). Noteworthy, however, cholesterol down-regulates BK channels and its acute depletion using methyl- $\beta$-cyclodextrin potentiates channel activity (Dopico and Bukiya, 2014). However, a recent study using native cerebral artery smooth muscle cells revealed that cholesterol enrichment stimulated BK channels, and this effect was driven by increases in cell membrane levels of $\beta_{1}$ subunits (Bukiya et al., 2021). In support to these findings, smooth muscle cells isolated from human coronary atherosclerotic plaque samples exhibited significantly higher channel activity than those obtained from coronary media segments (Wiecha et al., 1997). However, these findings should be interpreted with caution as cholesterol supplementation may directly modify the dynamic physical characteristics of the cell membrane, and consequently the conformation and function of the BK channel.

A long list of additional signaling molecules have been shown to influence BK channel activity including ethanol (Dopico et al., 1998; Bukiya et al., 2014a), paracrine mediators such as NO (Mistry and Garland, 1998) or adiponectin (Baylie et al., 2017); and hormones and circulating agents like angiotensin II (Zhang et al., 2014), leukotrienes (Bukiya et al., 2014b), ghrelin (Mladenov et al., 2008) or cannabinoids (Sade et al., 2006). Furthermore, BK channels are indirectly stimulated by a number of downstream second messengers resulting from the action of endogenous modulators such as adenosine and ATP, prostacyclin or CGRP (Cabell et al., 1994; Strøbaek et al., 1996a; Herzog et al., 2002; Tanaka et al., 2004).

\section{BK Channel Inhibitors and Blockers}

Venom from scorpions represent a rich reservoir of bioactive peptides, some of which have robust BK channel inhibitory properties. These toxin peptides display high potency and selectivity, constituting powerful molecular tools for the biophysical characterization of BK channels and the development of BK channel pharmacology. Charybdotoxin (ChTX), a 37-amino-acid peptide obtained from the scorpion Leiurus quinquestriatus hebraeus (Gimenez-Gallego et al., 1988), was the first "BK channel blocker" reported. This potent peptide toxin binds electrostatically to the outer face of the BK channel and physically blocks its activity by interfering with $\mathrm{K}^{+}$efflux through the ion conduction pathway. Despite its high-affinity, ChTX is known to block other subtypes of $\mathrm{K}^{+}$channels including voltage-dependent $\mathrm{K}^{+}$channels $\left(\mathrm{K}_{\mathrm{v}} 1.2, \mathrm{~K}_{\mathrm{v}} 1.3\right.$, and $\left.\mathrm{K}_{\mathrm{v}} 1.6\right)$ and intermediate-conductance calcium-activated $\mathrm{K}^{+}$channels (Judge and Bever, 2006; Panyi et al., 2006), a property that results in its lack of selectivity and thus, prompts the requirement to use more selective BK channel blockers. The 37-amino-acid peptide Iberiotoxin (IbTX), a toxin purified from the African scorpion Buthus tamulus, shares extensive sequence homology (i.e., $70 \%$ ) with ChTX with an identical peptide backbone configuration, but exhibits more selectivity for BK channels 
as it does not inhibit other $\mathrm{K}^{+}$channels apparently sensitive to ChTX (Galvez et al., 1990). The high selectivity of this toxin was determined by structural studies indicating that IbTX in fact binds to a different receptor on the external face of the BK channel which is allosterically coupled to the ChTXbinding site (Candia et al., 1992). This therefore, positions $\mathrm{IbTX}$ as a valuable pharmacological tool to study the structure and function of BK channels. In addition to ChTX and IbTX, a number of other toxin peptides have been purified from scorpion venom and similarly described as BK channel blockers with diverse and selective pharmacology, including Lq2 (Lucchesi et al., 1989), BmTx1/BmTx2 (Blanc et al., 1998), Lqh 15-1 (also called ChTx2; Marshall et al., 1994), and slotoxin (GarciaValdes et al., 2001). While all these peptide toxins are useful tools for experimentation, they do not display true potential as therapeutics given their inherent pharmaceutical disadvantages (e.g., rapid degradation, poor blood-brain permeability, ineffective orally active formulation) and poor reversibility.

A distinct group of highly selective and potent BK channel blockers include a series of non-peptide alkaloid molecules such as the fungal tremorgenic indole-diterpenes paxilline, penitrem $\mathrm{A}$ and lolitrem $\mathrm{B}$, and the organic amines tetraethylammonium (TEA), verapamil and ketamine. While these alkaloids are capable of inhibiting BK channels in a highly specific fashion, their respective structures and mechanisms of action differ considerably (Kaczorowski et al., 1996; Nardi et al., 2003). Among them, tremorgenic mycotoxins, which are known to elicit a neurotoxic disorder in cattle called "ryegrass staggers" syndrome, are the most potent and selective non-peptide blockers of BK channels to date (Norris et al., 1980). In particular, paxilline has been the most extensively used in experimentation due to its apparent high-specificity and reversibility of action. This largely rigid molecule potently blocks BK channels at low nanomolar concentrations ([nM]) by interacting with binding sites residing on the $\alpha$-subunit - distinct but allosterically coupled to those associated with ChTX (DeFarias et al., 1996; Sanchez and McManus, 1996). Additionally, a recent study from Zhou et al. (2020), identified a novel and highly specific site involved with paxilline-mediated inhibition that may represent a useful tool to further elucidate BK channel function as well as to design new modulators with promising clinical applications.

Quaternary amines such as TEA and its analogues belong to the group of organic amines able to block BK channels in a voltage-dependent manner but also a wide variety of other voltage-gated $\mathrm{K}^{+}$channels, lacking therefore of high selectivity and applicability. In contrast to the toxin peptides - which only binds to the outer face of the BK channel - TEA blocks BK channels through either the internal or external side of the membrane, implying a complex mechanism of action. However, it exhibits different affinities depending on its site of action (external vs. internal). Specifically, BK channels are more sensitive to external TEA, and this particularity is attributed to a phenylalanine ring located near the mouth of the channel pore (Heginbotham and MacKinnon, 1992). This well-defined binding site is selective for TEA and it seems to act as a filter to differentiate the diverse TEA analogs by size. Given its ability to block BK channels, TEA has been suggested as a possible treatment to improve the persistent hypotension associated with septic shock. However, a study using a BK channel $\alpha$ subunit knockout mouse line demonstrated that BK channels are not a potential therapeutic target for sepsis-induced hypotension, suggesting therefore that the pressor effect of TEA may be attributed to other potassium channel species ( $\mathrm{O}^{\prime}$ Brien et al., 2011).

BK channel activity is also sensitive to other organic amines including verapamil and ketamine, quinoline derivatives such as quinine and quinidine, and imidazole derivatives (clotrimazole). The antihypertensive and antiarrhythmic agent verapamil and its analogues, are potent $\mathrm{L}$-type $\mathrm{Ca}^{2+}$ channel blockers known to cause vasodilation and a decrease in arterial blood pressure. Verapamil is able to block BK channels (with an efficacy comparable to that reported for $\mathrm{Ca}^{2+}$ channels) by binding to a residue within the channel pore. The intravenous general anesthetic, ketamine is also reported to indirectly inhibit BK channels, and this effect is attenuated by increases in intracellular $\mathrm{Ca}^{2+}$ levels, suggesting that both ketamine and $\mathrm{Ca}^{2+}$ compete for the same binding site on the channel protein (Denson and Eaton, 1994). Among the quinoline derivatives, quinine and quinidine inhibit $\mathrm{K}^{+}$efflux through BK channels, a blockade characterized by fast flickering of the channel between the open and closed states with a consequent reduction in open channel amplitude (Wong, 1989; Mancilla and Rojas, 1990). In addition, the imidazole antimycotic P450-inhibitor clotrimazole is also capable of diminishing the open probability of BK channels without affecting single-channel conductance (Wu et al., 1999).

Furthermore, a number of cations including $\mathrm{H}^{+}, \mathrm{Na}^{+}, \mathrm{Cs}^{+}$ and $\mathrm{Ba}^{2+}$ are also known to bind to the $\mathrm{K}^{+}$-conduction pathway and block single-channel (i.e., unitary) currents through BK channels, thus constituting vital experimental tools in characterizing their multi-ion pore conduction mechanism.

Direct blockade of BK channels may offer therapeutic benefit in certain pathologies. However, the use of the abovementioned peptide or non-peptide BK channels blockers in the clinical setting has been extremely limited due to their poor pharmaceutical features. Thus, a demand for more targeted and selective drugs still exists for meaningful pharmacotherapy strategies and improved patient outcomes. It is clear that only through dedicated research and development initiatives, we can expect a novel BK channel inhibitor compound to satisfy strict criteria for specific channel targeting and clinically acceptable pharmacokinetics/pharmacodynamics properties in humans.

\section{BK Channel Activators and Openers}

Several synthetic and endogenous BK channels openers have been investigated at whole-cell and single channel levels using the patch-clamp technique in a diverse array of native vascular, non-vascular tissues from different animal species, and culture cell models. These small-molecule BK openers include the synthetic benzimidazoles NS004 and NS1619 (McKay et al., 1994; Lee et al., 1995a), the biaryl-amine flufenamic acid (Ottolia and Toro, 1994), the biarylurea 
NS1608 (Strøbaek et al., 1996b), the aryloxindol BMS-204352 (Gribkoff et al., 2001), the pyrrole derivative NS-8 (Tanaka et al., 2003), the indole-3-carboxylic acid esters CGS-7184 and CGS-7181 (Hu et al., 1997), and the natural modulator dihydrosoyasaponin-1 (Gribkoff et al., 1996). Among them, NS1619 has been widely studied as a potential therapeutic treatment for various conditions involving vascular and non-vascular smooth muscle such as shock-induced vascular hyporeactivity ( $\mathrm{Hu}$ et al., 2014), pulmonary hypertension (Revermann et al., 2014), bladder hyperactivity (La Fuente et al., 2014), and erectile dysfunction (Gonzalez-Corrochano et al., 2013). However, the therapeutic perspective of NS1619 is limited given its relatively low potency and selectivity. A more selective BK channel opener, NS11021, has been reported to protect the heart against ischemia-reperfusion injury (Bentzen et al., 2009), enhance erectile responses in rodents (Kun et al., 2009) and reduce excitability and contractility of detrusor smooth muscle in the urinary bladder (Layne et al., 2010). Finally, the GoSlo-SR family constitute a group of anthraquinone analogues with higher potency than NS11021, which has been suggested as a useful starting template for the design of more tissue-specific BK openers (Roy et al., 2012).

While these BK channel openers would offer some limited clinical applications for conditions of neuronal and muscular hyperexcitability, they have not borne meaningful fruit for the pharmaceutical industry as therapeutic treatments. High on the list of potential reasons for difficulty to utilize such agents is that they may induce epilepsy and/or paroxysmal movement disorder(s). It appears that the abnormally increased BK channel activity may paradoxically lead to an enhancement in excitability in certain cases by triggering rapid depolarization of action potentials and therefore, contributing these pathological conditions (Du et al., 2005). Nonetheless, Cheney et al. (2001) demonstrated that the fluoro-oxindole $\mathrm{BK}$ channel opener BMS-204352 might be selectively beneficial for the treatment of experimental traumatic brain injury, in this case induced by lateral fluid percussion, as its administration significantly improved neurologic motor deficits and prevented the extent of regional cerebral edema at $\sim 1-2$ weeks post-injury. This pharmacological agent was subsequently suggested as a promising therapeutic strategy for ischemic stroke as it was able to diminish neuronal excitability and excitatory transmitter release in a rodent model of stroke (Jensen, 2002).

\section{BK CHANNEL DIVERSITY}

\section{Post-transcriptional Modifications}

The pore-forming $\alpha$-subunits of the mammalian BK channel are encoded by only one gene (Slo1; KCNMA1) which displays extensive alternative splicing of pre-messenger RNA. The powerful regulatory strategy of alternative splicing allows a large number of phenotypic splice variants to be generated from a single gene with high degree of diversity, particularly with respect to their physiological roles, tissue distribution, and biophysical features such as apparent sensitivity to calcium/ voltage, unit conductance, activation/deactivation voltage range, and phosphorylation susceptibility by endogenous protein kinases or other intracellular signaling pathways (Tian et al., 2001; Chen et al., 2005; McCartney et al., 2005; Fodor and Aldrich, 2009). Alternative splicing also acts as a regulator of BK channel trafficking by finely tuning their cell surface expression according to certain physiological needs (Zarei et al., 2004; Singh et al., 2012). A variety of sites of alternative splicing within the $\alpha$-subunits have been identified, and the intracellular C-terminal domain comprises the majority of them (Shipston, 2001). Using transcript scanning, Chen et al. (2005) analyzed the biophysical profile of five distinct splice variants resulting from alternative splicing at a single site - the mammalian site of splicing $\mathrm{C} 2$ residing in the $\mathrm{C}$-terminal domain - and described the high variability among them in terms of functionality and biophysical properties. Thus, this widespread phenomenon represents a powerful mechanism to increase BK channel molecular heterogeneity and determine cellular excitability in a given tissue.

\section{Post-translational Modifications}

BK channel activity is robustly regulated by an eclectic array of major post-translational processes including phosphorylation, palmitoylation, glycosylation and ubiquitination (for an extensive review see Shipston and Tian, 2016). For instance, BK channels are potently and reversibly controlled by PKA-mediated phosphorylation in neurons and smooth muscle cells (Lee et al., 1995b; Zhou et al., 2000). Several studies have identified various putative PKA-mediated phosphorylation C-terminal motifs including $\mathrm{RQPS}_{899}$ and the stress regulated exon (STREX), with remarkable properties contributing to promote either BK channel activation and inhibition, respectively (Tian et al., 2004). Interestingly, the cytosolic C-terminal of the STREX insert can also undergo palmitoylation of a conserved cysteine-rich domain, providing a conditional gate for $\mathrm{BK}$ channel regulation by PKA phosphorylation (Tian et al., 2008). Additional cysteineenriched sites for palmitoylation have been identified independent of and outside the STREX insert - within the intracellular linker between the S0 and S1 transmembrane domains with key roles in controlling BK channel cell-surface expression (Jeffries et al., 2010). This complex cross-talk between palmitoylation and phosphorylation explains the dramatic functional diversity of the BK channel among different cell types and tissues. N-linked glycosylation has been also reported to control BK channel stability, trafficking, and function. While direct evidence in the $\alpha$ subunits is sparse, $\beta$ subunits have shown to be more susceptible to be $\mathrm{N}$-glycosylated at two residues (Asn 53 and Asn 90 in the human $\beta-4$ subunit) in the large extracellular loop (Wallner et al., 1996; Jin et al., 2002). Finally, multiple sites in the C-terminal domain of the $\alpha$ subunits may be exposed to subsequent polyubiquitination which in turn results in BK channel accumulation in the endoplasmic reticulum. Accordingly, transgenic mouse models lacking the ubiquitination molecular machinery exhibit increased levels of BK channels at the cell surface and develop neuronal hyperexcitability and spontaneous epileptic seizures. These 
findings effectively suggest that this post-translational mechanism is critical to prevent this neurological disorder through $\mathrm{BK}$ channels (Liu et al., 2014).

\section{Association With Auxiliary Subunits}

The association of the BK channel $\alpha$-subunit with tissue-specific auxiliary subunits generates considerable functional channel diversity in several tissues and cell types of large mammals. Two main families of auxiliary proteins have been extensively characterized thus far, the regulatory $\beta$ and $\gamma$ subunits.

Among the $\beta$ subunits, four different subtypes have been cloned (i.e., $\beta 1-\beta 4$ ) which share a similar architecture consisting of two transmembrane domains (i.e., TM1 and TM2) linked by a 100 -amino acid extracellular loop, and short intracellular C- and N-terminals. Although to a different extent, each $\beta$ subunits is generally able to impact the $\mathrm{Ca}^{2+}$ sensitivity, voltage dependence, and gating mechanisms of the BK channels they interact with, and thus, influence the cell membrane excitability in a tissue-specific manner (Brenner et al., 2000, 2005). Importantly, these auxiliary subunits may also alter the sensitivity of $\mathrm{BK}$ channels to regulatory molecules including hormones and lipids (King et al., 2006; Hoshi et al., 2013a; Martín et al., 2014). In regard to general tissue distribution, $\beta-1$ subunits are mainly found in vascular smooth muscle, urinary bladder and some areas of the brain, $\beta-2$ are highly expressed in chromaffin cells of the adrenal gland, pancreas, kidney and hippocampal neurons, $\beta-3$ is predominant in chromaffin cells, kidney, heart, liver and lung, and $\beta-4$ is almost exclusively expressed in the brain although it may be also found in smooth muscle (Contreras et al., 2013).

The family of auxiliary $\gamma$-subunits is equally composed of 4 distinct members $(1 \gamma-\gamma 4)$, encoded by four different genes. The $\gamma$-subunit is made up of a single transmembrane segment, a large extracellular domain containing leucine-rich repeat proteins, and a short intracellular C-terminal domain. Specifically,

\section{REFERENCES}

Adelman, J. P. (2016). SK channels and calmodulin. Channels 10, 1-6. doi: $10.1080 / 19336950.2015 .1029688$

Atkinson, N. S., Robertson, G. A., and Ganetzky, B. (1991). A component of calcium-activated potassium channels encoded by the Drosophila slo locus. Science 253, 551-555. doi: 10.1126/science. 1857984

Avdonin, V., Tang, X. D., and Hoshi, T. (2003). Stimulatory action of internal protons on Slo1 BK channels. Biophys. J. 84, 2969-2980. doi: 10.1016/ S0006-3495(03)70023-X

Barrett, J. N., Magleby, K. L., and Pallotta, B. S. (1982). Properties of single calcium-activated potassium channels in cultured rat muscle. J. Physiol. 331, 211-230. doi: 10.1113/jphysiol.1982.sp014370

Baylie, R., Ahmed, M., Bonev, A. D., Hill-Eubanks, D. C., Heppner, T. J., Nelson, M. T., et al. (2017). Lack of direct effect of adiponectin on vascular smooth muscle cell $\mathrm{BK}_{\mathrm{Ca}}$ channels or $\mathrm{Ca}^{2+}$ signaling in the regulation of small artery pressureinduced constriction. Physiol. Rep. 5:e13337. doi: 10.14814/phy2.13337

Bentzen, B. H., Osadchii, O., Jespersen, T., Hansen, R. S., Olensen, S. P., and Grunnet, M. (2009). Activation of big conductance $\mathrm{Ca}(2+)$-activated $\mathrm{K}(+)$ channels (BK) protects the heart against ischemia-reperfusion injury. Pflugers Arch. 457, 979-988. doi: 10.1007/s00424-008-0583-5

Berkefeld, H., Sailer, C. A., Bildl, W., Rohde, V., Thumfart, J. O., Eble, S., et al. (2006). BKCa-Cav channel complexes mediate rapid and localized $\mathrm{Ca}^{2+}$-activated $\mathrm{K}^{+}$signaling. Science 314, 615-620. doi: 10.1126/science.1132915 these leucine-rich repeat proteins are critical in modifying the BK channel activation profile (Yan and Aldrich, 2010, 2012). More recently, a novel regulatory subunit termed LINGO1 has been discovered and constitutes the subject of ongoing studies. This protein, which shares a number of structural characteristics with $\gamma_{1-4}$ subunits and has been associated with motor disorders and tremor such as Parkinson's disease and essential tremor, was found to be in close association with $\mathrm{BK}$ channels and reduced BK channel activity in culture models and human cerebellar tissues (Dudem et al., 2020).

\section{CONCLUDING REMARKS}

Many landmark studies have contributed to the understanding of BK channel structure and function. The reporting of the BK channel crystal structure had initially raised hopes about therapeutic potential, but difficulties generating a safe, reliable and specific pharmaceutical compound for therapy have been particularly problematic. The continued work to fully characterize the crystal structure(s) of the various BK channel accessory subunits may offer promise to provide alternative targets to modulate channel function and improve therapies. While such drugs and interventions may be some years away from clinical practice, efforts to study BK channel function using "laboratorybased" research compounds still provide important tools to further understand the various roles of $\mathrm{BK}$ channels in the context of cellular-, tissue-, and organ-specific studies.

\section{AUTHOR CONTRIBUTIONS}

MS and BDK wrote the manuscript, and designed the figures. Both authors contributed to the article and approved the submitted version.

Bezanilla, F. (2008). Ion channels: from conductance to structure. Neuron 60 , 456-468. doi: 10.1016/j.neuron.2008.10.035

Blanc, E., Romi-Lebrun, R., Bornet, O., Nakajima, T., and Darbon, H. (1998). Solution structure of two new toxins from the venom of the Chinese scorpion Buthus martensi Karsch blockers of potassium channels. Biochemistry 37, 12412-12418. doi: 10.1021/bi9809371

Bonev, A. D., Jaggar, J. H., Rubart, M., and Nelson, M. T. (1997). Activators of protein kinase $\mathrm{C}$ decrease $\mathrm{Ca}^{2+}$ spark frequency in smooth muscle cells from cerebral arteries. Am. J. Phys. 273, C2090-C2095. doi: 10.1152/ ajpcell.1997.273.6.C2090

Braun, M., Ramracheya, R., Bengtsson, M., Zhang, Q., Karanauskaite, J., Partridge, C., et al. (2008). Voltage-gated ion channels in human pancreatic beta-cells: electrophysiological characterization and role in insulin secretion. Diabetes 57, 1618-1628. doi: 10.2337/db07-0991

Brayden, J. E., and Nelson, M. T. (1992). Regulation of arterial tone by activation of calcium-dependent potassium channels. Science 256, 532-535. doi: 10.1126/ science. 1373909

Brelidze, T. I., and Magleby, K. L. (2004). Protons block BK channels by competitive inhibition with $\mathrm{K}^{+}$and contribute to the limits of unitary currents at high voltages. J. Gen. Physiol. 123, 305-319. doi: 10.1085/jgp.200308951

Brenner, R., Chen, Q. H., Vilaythong, A., Toney, G. M., Noebels, J. L., and Aldrich, R. W. (2005). BK channel beta4 subunit reduces dentate gyrus excitability and protects against temporal lobe seizures. Nat. Neurosci. 8, 1752-1759. doi: 10.1038/nn1573 
Brenner, R., Peréz, G. J., Bonev, A. D., Eckman, D. M., Kosek, J. C., Wiler, S. W., et al. (2000). Vasoregulation by the betal subunit of the calcium-activated potassium channel. Nature 407, 870-876. doi: 10.1038/35038011

Brzezinska, A. K., Gebremedhin, D., Chilian, W. M., Kalyanaraman, B., and Elliott, S. J. (2000). Peroxynitrite reversibly inhibits $\mathrm{Ca}(2+)$-activated $\mathrm{K}(+)$ channels in rat cerebral artery smooth muscle cells. Am. J. Physiol. Heart Circ. Physiol. 278, H1883-H1890. doi: 10.1152/ajpheart.2000.278.6.H1883

Bukiya, A. N., Kuntamallappanavar, G., Edwards, J., Singh, A. K., Shivakumar, B., and Dopico, A. M. (2014a). An alcohol-sensing site in the calcium- and voltage-gated, large conductance potassium (BK) channel. Proc. Natl. Acad. Sci. U. S. A. 111, 9313-9318. doi: 10.1073/pnas.1317363111

Bukiya, A. N., Leo, M. D., Jaggar, J. H., and Dopico, A. M. (2021). Cholesterol activates $\mathrm{BK}$ channels by increasing KCNMB1 protein levels in the plasmalemma. J. Biol. Chem. 296, 100381. doi: 10.1016/j.jbc.2021.100381

Bukiya, A. N., McMillan, J., Liu, J., Shivakumar, B., Parrill, A. L., and Dopico, A. M. (2014b). Activation of calcium- and voltage-gated potassium channels of large conductance by leukotriene B4. J. Biol. Chem. 289, 35314-35325. doi: 10.1074/jbc.M114.577825

Cabell, F., Weiss, D. S., and Price, J. M. (1994). Inhibition of adenosine-induced coronary vasodilation by block of large-conductance $\mathrm{Ca}(2+)$-activated $\mathrm{K}^{+}$ channels. Am. J. Phys. 267, H1455-H1460. doi: 10.1152/ ajpheart.1994.267.4.H1455

Candia, S., Garcia, M. L., and Latorre, R. (1992). Mode of action of iberiotoxin, a potent blocker of the large conductance $\mathrm{Ca}(2+)$-activated $\mathrm{K}^{+}$channel. Biophys. J. 63, 583-590. doi: 10.1016/S0006-3495(92)81630-2

Chen, L., Tian, L., MacDonald, S. H., McClafferty, H., Hammond, M. S., Huibant, J. M., et al. (2005). Functionally diverse complement of large conductance calcium- and voltage-activated potassium channel (BK) alphasubunits generated from a single site of splicing. J. Biol. Chem. 280, 33599-33609. doi: 10.1074/jbc.M505383200

Cheney, J. A., Weisser, J. D., Bareyre, F. M., Laurer, H. L., Saatman, K. E., Raghupathi, R., et al. (2001). The maxi-K channel opener BMS-204352 attenuates regional cerebral edema and neurologic motor impairment after experimental brain injury. J. Cereb. Blood Flow Metab. 21, 396-403. doi: 10.1097/00004647-200104000-00008

Contet, C., Goulding, S. P., Kuljis, D. A., and Barth, A. L. (2016). BK channels in the central nervous system. Int. Rev. Neurobiol. 128, 281-342. doi: 10.1016/ bs.irn.2016.04.001

Contreras, G. F., Castillo, K., Enrique, N., Carrasquel-Ursulaez, W., Castillo, J. P., Milesi, V., et al. (2013). A BK (Slo1) channel journey from molecule to physiology. Channels 7, 442-458. doi: 10.4161/chan.26242

Contreras, G. F., Neely, A., Alvarez, O., Gonzalez, C., and Latorre, R. (2012). Modulation of BK channel voltage gating by different auxiliary $\beta$ subunits. Proc. Natl. Acad. Sci. U. S. A. 109, 18991-18996. doi: 10.1073/pnas.1216953109

Cox, D. H., Cui, J., and Aldrich, R. W. (1997). Allosteric gating of a large conductance Ca-activated $\mathrm{K}^{+}$channel. J. Gen. Physiol. 110, 257-281. doi: 10.1085/jgp.110.3.257

Cui, J., Cox, D. H., and Aldrich, R. W. (1997). Intrinsic voltage dependence and $\mathrm{Ca}^{2+}$ regulation of mslo large conductance Ca-activated $\mathrm{K}^{+}$channels. J. Gen. Physiol. 109, 647-673. doi: 10.1085/jgp.109.5.647

Dabertrand, F., Nelson, M. T., and Brayden, J. E. (2012). Acidosis dilates brain parenchymal arterioles by conversion of calcium waves to sparks to activate BK channels. Circ. Res. 110, 285-294. doi: 10.1161/CIRCRESAHA.111. 258145

DeFarias, F. P., Carvalho, M. F., Lee, S. H., Kaczorowski, G. J., and Suarez-Kurtz, G. (1996). Effects of the $\mathrm{K}^{+}$channel blockers paspalitrem-C and paxilline on mammalial smooth muscle. Eur. J. Pharmacol. 314, 123-128. doi: 10.1016/ s0014-2999(96)00540-7

Denson, D. D., and Eaton, D. C. (1994). Ketamine inhibition of large conductance $\mathrm{Ca}(2+)$-activated $\mathrm{K}^{+}$channels is modulated by intracellular $\mathrm{Ca}^{2+} . \mathrm{Am}$. J. Phys. 267, C1452-C1458. doi: 10.1152/ajpcell.1994.267.5.C1452

Dopico, A. M., Anantharam, V., and Treistman, S. N. (1998). Ethanol increases the activity of $\mathrm{Ca}(++)$-dependent $\mathrm{K}^{+}$(mslo) channels: functional interaction with cytosolic Ca++. J. Pharmacol. Exp. Ther. 284, 258-268.

Dopico, A. M., and Bukiya, A. N. (2014). Lipid regulation of BK channel function. Front. Physiol. 5:312. doi: 10.3389/fphys.2014.00312

Dopico, A. M., and Bukiya, A. N. (2017). Regulation of $\mathrm{Ca}^{2+}$-sensitive $\mathrm{K}^{+}$ channels by cholesterol and bile acids via distinct channel subunits and sites. Curr. Top. Membr. 80, 53-93. doi: 10.1016/bs.ctm.2017.07.001
Dopico, A. M., Bukiya, A. N., and Jaggar, J. H. (2018). Calcium- and voltagegated BK channels in vascular smooth muscle. Pflugers Arch. 470, 1271-1289. doi: 10.1007/s00424-018-2151-y

Dopico, A. M., Bukiya, A. N., and Singh, A. K. (2012). Large conductance, calcium- and voltage-gated potassium (BK) channels: regulation by cholesterol. Pharmacol. Ther. 135, 133-150. doi: 10.1016/j.pharmthera.2012. 05.002

Doré, S. (2002). Decreased activity of the antioxidant heme oxygenase enzyme: implications in ischemia and in Alzheimer's disease. Free Radic. Biol. Med. 32, 1276-1282. doi: 10.1016/s0891-5849(02)00805-5

Du, W., Bautista, J. F., Yang, H., Diez-Sampedro, A., You, S. A., Wang, L., et al. (2005). Calcium-sensitive potassium channelopathy in human epilepsy and paroxysmal movement disorder. Nat. Genet. 37, 733-738. doi: 10.1038/ ng1585

Dudem, S., Large, R. J., Kulkarni, S., McClafferty, H., Tikhonova, I. G., Sergeant, G. P., et al. (2020). LINGO1 is a regulatory subunit of large conductance, $\mathrm{Ca}^{2+}$-activated potassium channels. Proc. Natl. Acad. Sci. U. S. A. 117, 2194-2200. doi: 10.1073/pnas.1916715117

Elkins, T., Ganetzky, B., and Wu, C. F. (1986). A Drosophila mutation that eliminates a calcium-dependent potassium current. Proc. Natl. Acad. Sci. U. S. A. 83, 8415-8419. doi: 10.1073/pnas.83.21.8415

Fanger, C. M., Ghanshani, S., Longsdon, N. J., Rauer, H., Kalman, K., Zhou, J., et al. (1999). Calmodulin mediates calcium-dependent activation of the intermediate conductance KCa channel, IKCa1. J. Biol. Chem. 274, 5746-5754. doi: 10.1074/jbc.274.9.5746

Ferguson, W. B. (1991). Competitive $\mathrm{Mg}^{2+}$ block of a large-conductance, $\mathrm{Ca}(2+)$ activated $\mathrm{K}^{+}$channel in rat skeletal muscle. $\mathrm{Ca}^{2+}, \mathrm{Sr}^{2+}$, and $\mathrm{Ni}^{2+}$ also block. J. Gen. Physiol. 98, 163-181. doi: 10.1085/jgp.98.1.163

Filosa, J. A., Bonev, A. D., Straub, S. V., Meredith, A. L., Wilkerson, M. K. Aldrich, R. W., et al. (2006). Local potassium signaling couples neuronal activity to vasodilation in the brain. Nat. Neurosci. 9, 1397-1403. doi: 10.1038/ nn1779

Fodor, A. A., and Aldrich, R. W. (2009). Convergent evolution of alternative splices at domain boundaries of the BK channel. Annu. Rev. Physiol. 71, 19-36. doi: 10.1146/annurev.physiol.010908.163124

Galvez, A., Gimenez-Gallego, G., Reuben, J. P., Roy-Contancin, L., Feigenbaum, P., Kaczorowski, G. J., et al. (1990). Purification and characterization of a unique, potent, peptidyl probe for the high conductance calcium-activated potassium channel from venom of the scorpion Buthus tamulus. J. Biol. Chem. 265, 11083-11090.

Ganitkevich, V., and Isenberg, G. (1990). Isolated Guinea pig coronary smooth muscle cells. Acetylcholine induces hyperpolarization due to sarcoplasmic reticulum calcium release activating potassium channels. Circ. Res. 67, 525-528. doi: 10.1161/01.res.67.2.525

Garcia-Valdes, J., Zamudio, F. Z., Toro, L., and Possani, L. D. (2001). Slotoxin, alphaKTx1.11, a new scorpion peptide blocker of MaxiK channels that differentiates between alpha and alpha+beta (betal or beta4) complexes. FEBS Lett. 505, 369-373. doi: 10.1016/s0014-5793(01)02791-0

Gebremedhin, D., Bonnet, P., Greene, A. S., England, S. K., Rusch, N. J., Lombard, J. H., et al. (1994). Hypoxia increases the activity of $\mathrm{Ca}(2+)$ sensitive $\mathrm{K}^{+}$channels in cat cerebral arterial muscle cell membranes. Pflugers Arch. 428, 621-630. doi: 10.1007/BF00374586

Gimenez-Gallego, G., Navia, M. A., Reuben, J. P., Katz, G. M., Kaczorowski, G. J., and Garcia, M. L. (1988). Purification, sequence, and model structure of charybdotoxin, a potent selective inhibitor of calcium-activated potassium channels. Proc. Natl. Acad. Sci. U. S. A. 85, 3329-3333. doi: 10.1073/ pnas.85.10.3329

Gonzalez-Corrochano, R., La Fuente, J., Cuevas, P., Fernandez, A., Chen, M., Saenz de Tejada, I., et al. (2013). $\mathrm{Ca}^{2+}$-activated $\mathrm{K}^{+}$cannel (KCa) stimulation improves relaxant capacity of PDE5 inhibitors in human penile arteries and recovers the reduced efficacy of PDE5 inhibition in diabetic erectile dysfunction. Br. J. Pharmacol. 169, 449-461. doi: 10.1111/bph.12143

Gonzalez-Perez, V., and Lingle, C. J. (2019). Regulation of BK channels by beta and gamma subunits. Annu. Rev. Physiol. 81, 113-137. doi: 10.1146/ annurev-physiol-022516-034038

Gribkoff, V. K., Lum-Ragan, J. T., Boissard, C. G., Post-Munson, D. J., Meanwell, N. A., Starrett, J. E. Jr., et al. (1996). Effects of channel modulators on cloned large-conductance calcium-activated potassium channels. Mol. Pharmacol. 50, 206-217. 
Gribkoff, V. K., Starrett, J. E. Jr., Dworetzky, S. I., Hewawasam, P., Boissard, C. G., Cook, D. A., et al. (2001). Targeting acute ischemic stroke with a calciumsensitive opener of maxi-K potassium channels. Nat. Med. 7, 471-477. doi: $10.1038 / 86546$

Gutterman, D. D., and Durand, M. J. (2014). Vascular dysfunction in diabetes mellitus: large conductance calcium-activated potassium channels as part of a subsarcolemmal signaling soiree. Circ. Res. 114, 588-590. doi: 10.1161/ CIRCRESAHA.114.303203

Hayashi, Y., Morinaga, S., Zhang, J., Satoh, Y., Meredith, A. L., Nakata, T., et al. (2016). BK channels in microglia are required for morphine-induced hyperalgesia. Nat. Commun. 7:11697. doi: 10.1038/ncomms11697

Heginbotham, L., and MacKinnon, R. (1992). The aromatic binding site for tetraethylammonium ion on potassium channels. Neuron 8, 483-491. doi: 10.1016/0896-6273(92)90276-j

Herrera, G. M., Etherton, B., Nausch, B., and Nelson, M. T. (2005). Negative feedback regulation of nerve-mediated contractions by $\mathrm{KCa}$ channels in mouse urinary bladder smooth muscle. Am. J. Physiol. Regul. Integr. Comp. Physiol. 289, R402-R409. doi: 10.1152/ajpregu.00488.2004

Herzog, M., Scherer, E. Q., Albrecht, B., Rorabaugh, B., Scofield, M. A., and Wangemann, P. (2002). CGRP receptors in the gerbil spiral modiolar artery mediate a sustained vasodilation via a transient cAMP-mediated $\mathrm{Ca}^{2+}$-decrease. J. Membr. Biol. 189, 225-236. doi: 10.1007/s00232-002-1017-5

Hite, R. K., Tao, X., and MacKinnon, R. (2017). Structural basis for gating the high conductance $\mathrm{Ca}^{2+}$-activated $\mathrm{K}^{+}$channel. Nature 541, 52-57. doi: 10.1038/nature20775

Horrigan, F. T., and Aldrich, R. W. (1999). Allosteric voltage gating of potassium channels II. Mslo channel gating charge movement in the absence of $\mathrm{Ca}(2+)$. J. Gen. Physiol. 114, 305-336. doi: 10.1085/jgp.114.2.305

Horrigan, F. T., and Aldrich, R. W. (2002). Coupling between voltage sensor activation, $\mathrm{Ca}^{2+}$ binding and channel opening in large conductance (BK) potassium channels. J. Gen. Physiol. 120, 267-305. doi: 10.1085/jgp.20028605

Horrigan, F. T., Cui, J., and Aldrich, R. W. (1999). Allosteric voltage gating of potassium channels I. Mslo ionic currents in the absence of $\mathrm{Ca}(2+)$. J. Gen. Physiol. 114, 277-304. doi: 10.1085/jgp.114.2.277

Horrigan, F. T., Heinemann, S. H., and Hoshi, T. (2005). Heme regulates allosteric activation of the Slo1 BK channel. J. Gen. Physiol. 126, 7-21. doi: 10.1085/jgp.200509262

Hoshi, T., Tian, Y., Xu, R., Heinemann, S. H., and Hou, S. (2013a). Mechanism of the modulation of BK potassium channel complexes with different auxiliary subunit compositions by the omega-3 fatty acid DHA. Proc. Natl. Acad. Sci. U. S. A. 110, 4822-4827. doi: 10.1073/pnas.1222003110

Hoshi, T., Wissuwa, B., Tian, Y., Tajima, N., Xu, R., Bauer, M., et al. (2013b). Omega-3 fatty acids lower blood pressure by directly activating largeconductance $\mathrm{Ca}^{2+}$-dependent $\mathrm{K}^{+}$channels. Proc. Natl. Acad. Sci. U. S. A. 110, 4816-4821. doi: 10.1073/pnas.1221997110

Hou, S., Horrigan, F. T., Xu, R., Heinemann, S. H., and Hoshi, T. (2009). Comparative effects of $\mathrm{H}+$ and $\mathrm{Ca}^{2+}$ on large-conductance $\mathrm{Ca}^{2+}$ - and voltagegated Slo1 $\mathrm{K}^{+}$channels. Channels 3, 249-258. doi: 10.4161/chan.3. 4.9253

Hu, S., Fink, C. A., Kim, H. S., and Lappe, R. W. (1997). Novel and potent BK channel openers: CGS 7181 and its analogs. Drug Dev. Res. 41, 10-21. doi: 10.1002/(SICI)1098-2299(199705)41:1<10::AID-DDR2>3.0.CO;2-V

Hu, L., Shao, L. R., Chavoshy, S., Gu, N., Trieb, M., Behrens, R., et al. (2001). Presynaptic $\mathrm{Ca}^{2+}$-activated $\mathrm{K}^{+}$channels in glutamatergic hippocampal terminals and their role in spike repolarization and regulation of transmitter release. J. Neurosci. 21:9585. doi: 10.1523/JNEUROSCI.21-24-09585.2001

Hu, L., Shi, J., Ma, Z., Krishnamoorthy, G., Sieling, F., Zhang, G., et al. (2003). Participation of the $\mathrm{S} 4$ voltage sensor in the $\mathrm{Mg}^{2+}$-dependent activation of large conductance (BK) $\mathrm{K}^{+}$channels. Proc. Natl. Acad. Sci. U. S. A. 100, 10488-10493. doi: 10.1073/pnas. 1834300100

Hu, Y., Yang, G., Xiao, X., Liu, L., and Li, T. (2014). Bkca opener, NS1619 pretreatment protects against shock-induced vascular hyporeactivity through PDZ-Rho GEF-RhoA-Rho kinase pathway in rats. J. Trauma Acute Care Surg. 76, 394-401. doi: 10.1097/TA.0b013e3182aa2d98

$\mathrm{Hu}, \mathrm{X}$. Q., and Zhang, L. (2012). Function and regulation of large conductance $\mathrm{Ca}(2+)$-activated $\mathrm{K}^{+}$channel in vascular smooth muscle cells. Drug Discov. Today 17, 974-987. doi: 10.1016/j.drudis.2012.04.002

Imlach, W. L., Finch, S. C., Dunlop, J., Meredith, A. L., Aldrich, R. W., and Dalziel, J. E. (2008). The molecular mechanism of "ryegrass staggers," a neurological disorder of $\mathrm{K}^{+}$channels. J. Pharmacol. Exp. Ther. 327, 657-664. doi: 10.1124/jpet.108.143933

Jaggar, J. H., Li, A., Parfenova, H., Liu, J., Umstot, E. S., Dopico, A. M., et al. (2005). Heme is a carbon monoxide receptor for large-conductance $\mathrm{Ca}^{2+}$. activated $\mathrm{K}^{+}$channels. Circ. Res. 97, 805-812. doi: 10.1161/01.RES.0000186180. $47148.7 \mathrm{~b}$

Jeffries, O., Geiger, N., Rowe, I. C. M., Tian, L., McClafferty, H., Chen, L., et al. (2010). Palmitoylation of the S0-S1 linker regulates cell surface expression of voltage- and calcium-activated potassium (BK) channels. J. Biol. Chem. 285, 33307-33314. doi: 10.1074/jbc.M110.153940

Jensen, B. S. (2002). BMS-204352: a potassium channel opener developed for the treatment of stroke. CNS Drug Rev. 8, 353-360. doi: 10.1111/j.1527-3458. 2002.tb00233.x

Jiang, Y., Lee, A., Chen, J., Cadene, M., Chait, B. T., and MacKinnon, R. (2002). Crystal structure and mechanism of a calcium-gated potassium channel. Nature 417, 515-522. doi: 10.1038/417515a

Jiao, H., Arner, P., Hoffstedt, J., Brodin, D., Dubern, B., Czernichow, S., et al. (2011). Genome wide association study identifies KCNMA1 contributing to human obesity. BMC Med. Genet. 4:51. doi: 10.1186/1755-8794-4-51

Jin, P., Weiger, T. M., and Levitan, I. B. (2002). Reciprocal modulation between the alpha and beta 4 subunits of hSlo calcium-dependent potassium channels. J. Biol. Chem. 277, 43724-43729. doi: 10.1074/jbc.M205795200

Judge, S. I., and Bever, C. T. Jr. (2006). Potassium channel blockers in multiple sclerosis: neuronal $\mathrm{Kv}$ channels and effects of symptomatic treatment. Pharmacol. Ther. 111, 224-259. doi: 10.1016/j.pharmthera.2005.10.006

Kaczorowski, G. J., Knaus, H. G., Leonard, R. J., McManus, O. B., and Garcia, M. L. (1996). High-conductance calcium-activated potassium channels; structure, pharmacology, and function. J. Bioenerg. Biomembr. 28, 255-267. doi: 10.1007/BF02110699

King, J. T., Lovell, P. V., Rishniw, M., Kotlikoff, M. I., Zeeman, M. L., and McCobb, D. P. (2006). Beta2 and beta4 subunits of BK channels confer differential sensitivity to acute modulation by steroid hormones. J. Neurophysiol. 95, 2878-2888. doi: 10.1152/jn.01352.2005

Knot, H. J., Standen, N. B., and Nelson, M. T. (1998). Ryanodine receptors regulate arterial diameter and wall $\left[\mathrm{Ca}^{2+}\right]$ in cerebral arteries of rat via $\mathrm{Ca}^{2+}$-dependent $\mathrm{K}^{+}$channels. J. Physiol. 508, 211-221. doi: 10.1111/j.14697793.1998.211br.x

Koval, O. M., Fan, Y., and Rothberg, B. S. (2007). A role for the S0 transmembrane segment in voltage-dependent gating of BK channels. J. Gen. Physiol. 129, 209-220. doi: 10.1085/jgp.200609662

Krishnamoorthy-Natarajan, G., and Koide, M. (2016). BK channels in the vascular system. Int. Rev. Neurobiol. 128, 401-438. doi: 10.1016/bs. irn.2016.03.017

Kumar, P. (2007). Sensing hypoxia in the carotid body: from stimulus to response. Essays Biochem. 43, 43-60. doi: 10.1042/BSE0430043

Kun, A., Matchkov, V. V., Stankevicius, E., Nardi, A., Hughes, A. D., Kirkeby, H. J., et al. (2009). NS11021, a novel opener of large-conductance $\mathrm{Ca}(2+)$-activated $\mathrm{K}(+)$ channels, enhances erectile responses in rats. Br. J. Pharmacol. 158, 1465-1476. doi: 10.1111/j.1476-5381.2009.00404.x

Kyle, B. D., Bradley, E., Large, R., Sergeant, G. P., McHale, N. G., Thornbury, K. D., et al. (2013). Mechanisms underlying activation of transient BK current in rabbit urethral smooth muscle cells and its modulation by IP3-generating agonists. Am. J. Physiol. Cell Physiol. 305, C609-C622. doi: 10.1152/ ajpcell.00025.2013

La Fuente, J. M., Fernandez, A., Cuevas, P., Gonzalez-Corrochano, R., Chen, M. X., and Angulo, J. (2014). Stimulation of large-conductance calcium-activated potassium channels inhibits neurogenic contraction of human bladder from patients with urinary symptoms and reverses acetic acid-induced bladder hyperactivity in rats. Eur. J. Pharmacol. 753, 68-76. doi: 10.1016/j. ejphar.2014.03.060

Lai, L. H., Wang, R. X., Jiang, W. P., Yang, X. J., Song, J. P., Li, X. R., et al. (2009). Effects of docosahexaenoic acid on large-conductance $\mathrm{Ca}^{2+}$-activated $\mathrm{K}^{+}$channels and voltage-dependent $\mathrm{K}^{+}$channels in rat coronary artery smooth muscle cells. Acta Pharmacol. Sin. 30, 314-320. doi: 10.1038/aps. 2009.7

Latorre, R., Castillo, K., Carrasquel-Ursulaez, W., Sepulveda, R. V., Gonzalez-Nilo, F., Gonzalez, C., et al. (2017). Molecular determinants of BK channel functional diversity and functioning. Physiol. Rev. 97, 39-87. doi: 10.1152/physrev. 00001.2016 
Latorre, R., Oberhauser, A., Labarca, P., and Alvarez, O. (1989). Varieties of calcium-activated potassium channels. Annu. Rev. Physiol. 51, 385-399. doi: 10.1146/annurev.ph.51.030189.002125

Latorre, R., Vergara, C., and Hidalgo, C. (1982). Reconstitution in planar lipid bilayers of a $\mathrm{Ca}^{2+}$-dependent $\mathrm{K}^{+}$channel from transverse tubule membranes isolated from rabbit skeletal muscle. Proc. Natl. Acad. Sci. U. S. A. 79, 805-809. doi: 10.1073/pnas.79.3.805

Laumonnier, F., Roger, S., Guérin, P., Molinari, F., M'rad, R., Cahard, D., et al. (2006). Association of a functional deficit of the BKCa channel, a synaptic regulator of neuronal excitability, with autism and mental retardation. Am. J. Psychiatry 163, 1622-1629. doi: 10.1176/ajp.2006.163.9.1622

Layne, J. J., Nausch, B., Olensen, S. P., and Nelson, M. T. (2010). BK channel activation by NS11021 decreases excitability and contractility of urinary bladder smooth muscle. Am. J. Physiol. Regul. Integr. Comp. Physiol. 298, 378-384. doi: 10.1152/ajpregu.00458.2009

Lee, U. S., and Cui, J. (2010). BK channel activation: structural and functional insights. Trends Neurosci. 33, 415-423. doi: 10.1016/j.tins.2010.06.004

Lee, S., Park, M., So, I., and Earm, Y. E. (1994). NADH and NAD modulates $\mathrm{Ca}(2+)$-activated $\mathrm{K}^{+}$channels in small pulmonary arterial smooth muscle cells of the rabbit. Pflugers Arch. 427, 378-380. doi: 10.1007/BF00374548

Lee, K., Rowe, I. C., and Ashford, M. L. (1995a). NS 1619 activates BKCa channel activity in rat cortical neurones. Eur. J. Pharmacol. 280, 215-219. doi: 10.1016/0014-2999(95)00251-f

Lee, K., Rowe, I. C., and Ashford, M. L. (1995b). Characterization of an ATP-modulated large conductance $\mathrm{Ca}(2+)$-activated $\mathrm{K}^{+}$channel present in rat cortical neurones. J. Physiol. 488, 319-337. doi: 10.1113/jphysiol.1995. sp020969

Liao, Y., Kristiansen, A. M., Oksvold, C. P., Tuvnes, F. A., Gu, N., Runden-Pran, E., et al. (2010). Neuronal $\mathrm{Ca}^{2+}$-activated $\mathrm{K}^{+}$channels limit brain infarction and promote survival. PLoS One 5:e15601. doi: 10.1371/ journal.pone.0015601

Liman, E. R., Hess, P., Weaver, F., and Koren, G. (1991). Voltage-sensing residues in the S4 region of a mammalian $\mathrm{K}^{+}$channel. Nature 353, 752-756. doi: $10.1038 / 353752 \mathrm{a} 0$

Liu, Y., Terata, K., Chai, Q., Li, H., Kleinman, L. H., and Gutterman, D. D. (2002). Peroxynitrite inhibits $\mathrm{Ca}^{2+}$-activated $\mathrm{K}^{+}$channel activity in smooth muscle of human coronary arterioles. Circ. Res. 91, 1070-1076. doi: 10.1161/01. res.0000046003.14031.98

Liu, J., Ye, J., Zou, X., Xu, Z., Feng, Y., Zou, X., et al. (2014). CRL4A(CRBN) E3 ubiquitin ligase restricts BK channel activity and prevents epileptogenesis. Nat. Commun. 5:3924. doi: 10.1038/ncomms4924

Liu, G., Zakharov, S. I., Yang, L., Deng, S. X., Landry, D. W., Karlin, A., et al. (2008). Position and role of the BK channel alpha subunit S0 helix inferred from disulfide crosslinking. J. Gen. Physiol. 131, 537-548. doi: 10.1085/ jgp.200809968

Logothetis, D. E., Kammen, B. F., Lindpaintner, K., Bisbas, D., and Nadal-Ginard, B. (1993). Gating charge differences between two voltage-gated $\mathrm{K}^{+}$channels are due to the specific charge content of their respective S4 regions. Neuron 10, 1121-1129. doi: 10.1016/0896-6273(93)90060-5

Lopez, G. A., Jan, Y. N., and Jan, L. Y. (1991). Hydrophobic substitution mutations in the S4 sequence alter voltage-dependent gating in shaker $\mathrm{K}^{+}$ channels. Neuron 7, 327-336. doi: 10.1016/0896-6273(91)90271-Z

Lucchesi, K., Ravindran, A., Young, H., and Moczydlowski, E. (1989). Analysis of the blocking activity of charybdotoxin homologs and iodinated derivatives against $\mathrm{Ca}^{2+}$-activated $\mathrm{K}^{+}$channels. J. Membr. Biol. 109, 269-281. doi: 10.1007/ BF01870284

Ma, Z., Lou, X. J., and Horrigan, F. T. (2006). Role of charged residues in the S1-S4 voltage sensor of BK channels. J. Gen. Physiol. 127, 309-328. doi: 10.1085 /jgp.200509421

Mancilla, E., and Rojas, E. (1990). Quinine blocks the high conductance, calcium-activated potassium channel in rat pancreatic beta-cells. FEBS Lett. 260, 105-108. doi: 10.1016/0014-5793(90)80078-w

Manzanares, D., Gonzalez, C., Ivonnet, P., Chen, R. S., Valencia-Gattas, M., Conner, G. E., et al. (2011). Functional apical large conductance, $\mathrm{Ca}^{2+}$ activated, and voltage-dependent $\mathrm{K}^{+}$channels are required for maintenance of airway surface liquid volume. J. Biol. Chem. 286, 19830-19839. doi: 10.1074/jbc.M110.185074

Markwardt, F., and Isenberg, G. (1992). Gating of maxi $\mathrm{K}^{+}$channels studied by $\mathrm{Ca}^{2+}$ concentration jumps in excised inside-out multi-channel patches (myocytes from Guinea pig urinary bladder). J. Gen. Physiol. 99, 841-862. doi: 10.1085 /jgp.99.6.841

Marshall, D. L., Vatanpour, H., Harvey, A. L., Boyot, P., Pinkasfeld, S., Doljansky, Y., et al. (1994). Neuromuscular effects of some potassium channel blocking toxins from the venom of the scorpion Leiurus quinquestriatus hebreus. Toxicon 32, 1433-1443. doi: 10.1016/0041-0101(94)90415-4

Martín, P., Moncada, M., Enrique, N., Asuaje, A., Valdez Capuccino, J. M., Gonzalez, C., et al. (2014). Arachidonic acid activation of BKCa (Slo1) channels associated to the $\beta 1$-subunit in human vascular smooth muscle cells. Pflugers Arch. 466, 1779-1792. doi: 10.1007/s00424-013-1422-x

Marty, A. (1981). Ca-dependent K channels with large unitary conductance in chromaffin cell membranes. Nature 291, 497-500. doi: 10.1038/291497a0

Marty, A. (1989). The physiological role of calcium-dependent channels. Trends Neurosci. 12, 420-424. doi: 10.1016/0166-2236(89)90090-8

McCartney, C. E., McClafferty, H., Huibant, J. M., Rowan, E. G., Shipston, M. J., and Rowe, I. C. (2005). A cysteine-rich motif confers hypoxia sensitivity to mammalian large conductance voltage- and Ca-activated $\mathrm{K}(\mathrm{BK})$ channel alpha-subunits. Proc. Natl. Acad. Sci. U. S. A. 102, 17870-17876. doi: 10.1073/ pnas.0505270102

McKay, M. C., Dworetzky, S. I., Meanwell, N. A., Olesen, S. P., Reinhart, P. H., Levitan, I. B., et al. (1994). Opening of large-conductance calcium-activated potassium channels by the substituted benzimidazolone NS004. J. Neurophysiol. 71, 1873-1882. doi: 10.1152/jn.1994.71.5.1873

McLarnon, J. G., and Sawyer, D. (1993). Effects of divalent cations on the activation of a calcium-dependent potassium channel in hippocampal neurons. Pflugers Arch. 424, 1-8. doi: 10.1007/BF00375095

Meera, P., Wallner, M., Song, M., and Toro, L. (1997). Large conductance voltage- and calcium-dependent $\mathrm{K}^{+}$channel, a distinct member of voltagedependent ion channels with seven N-terminal transmembrane segments (S0-S6), an extracellular $\mathrm{N}$ terminus, and an intracellular (S9-S10) C terminus. Proc. Natl. Acad. Sci. U. S. A. 94, 14066-14071. doi: 10.1073/pnas.94.25.14066

Minami, K., Fukuzawa, K., and Nakaya, Y. (1993a). Protein kinase C inhibits the $\mathrm{Ca}(2+)$-activated $\mathrm{K}^{+}$channel of cultured porcine coronary artery smooth muscle cells. Biochem. Biophys. Res. Commun. 190, 263-269. doi: 10.1006/ bbrc. 1993.1040

Minami, K., Fukuzawa, K., Nakaya, Y., Zeng, X., and R., and Inoue, I., (1993b). Mechanism of activation of the $\mathrm{Ca}(2+)$-activated $\mathrm{K}^{+}$channel by cyclic AMP in cultured porcine coronary artery smooth muscle cells. Life Sci. 53, 1129-1135. doi: 10.1016/0024-3205(93)90549-i

Miranda-Rottmann, S., Kozlov, A. S., and Hudspeth, A. J. (2010). Highly specific alternative splicing of transcripts encoding BK channels in the chicken's cochlea is a minor determinant of the tonotopic gradient. Mol. Cell. Biol. 30, 3646-3660. doi: 10.1128/MCB.00073-10

Mistry, D. K., and Garland, C. J. (1998). Nitric oxide (NO)-induced activation of large conductance $\mathrm{Ca}^{2+}$-dependent $\mathrm{K}^{+}$channels $(\mathrm{BK}(\mathrm{Ca})$ ) in smooth muscle cells isolated from the rat mesenteric artery. Br. J. Pharmacol. 124, 1131-1140. doi: $10.1038 /$ sj.bjp.0701940

Miyoshi, H., and Nakaya, Y. (1995). Calcitonin gene-related peptide activates the $\mathrm{K}^{+}$channels of vascular smooth muscle cells via adenylate cyclase. Basic Res. Cardiol. 90, 332-336. doi: 10.1007/BF00797911

Mladenov, M. I., Hristov, K. L., Dimitrova, D. Z., Schubert, R., Lubomirov, L. T., Gjorgoski, I. K., et al. (2008). Ghrelin signaling in Guinea-pig femoral artery smooth muscle cells. Acta Physiol. 194, 195-206. doi: 10.1111/j.1748-1716.2008.01880.x

Morales, E., Cole, W. C., Remillard, C. V., and Leblane, N. (1996). Block of large conductance $\mathrm{Ca}(2+)$-activated $\mathrm{K}^{+}$channels in rabbit vascular myocytes by internal $\mathrm{Mg}^{2+}$ and $\mathrm{Na}^{+}$. J. Physiol. 495, 701-716. doi: 10.1113/jphysiol.1996. sp021627

N'Gouemo, P. (2011). Targeting BK (big potassium) channels in epilepsy. Expert Opin. Ther. Targets 15, 1283-1295. doi: 10.1517/14728222.2011.620607

N'Gouemo, P. (2014). BKCa channel dysfunction in neurological diseases. Front. Physiol. 5:373. doi: 10.3389/fphys.2014.00373

Nardi, A., Calderone, V., Chericoni, S., and Morelli, I. (2003). Natural modulators of large-conductance calcium-activated potassium channels. Planta Med. 69, 885-892. doi: 10.1055/s-2003-45095

Navaratnam, D. S., Bell, T. J., Tu, T. D., Cohen, E. L., and Oberholtzer, J. C. (1997). Differential distribution of $\mathrm{Ca}^{2+}$-activated $\mathrm{K}^{+}$channel splice variants among hair cells along the tonotopic axis of the chick cochlea. Neuron 19, 1077-1085. doi: 10.1016/s0896-6273(00)80398-0 
Nelson, M. T., Cheng, H., Rubart, M., Santana, L. F., Bonev, A. D., Knot, H. J., et al. (1995). Relaxation of arterial smooth muscle by calcium sparks. Science 270, 633-637. doi: 10.1126/science.270.5236.633

Nelson, M. T., and Quayle, J. M. (1995). Physiological roles and properties of potassium channels in arterial smooth muscle. Am. J. Phys. 268, C799-C822. doi: 10.1152/ajpcell.1995.268.4.C799

Norris, P. J., Smith, C. C., De Belleroche, J., Bradford, H. F., Mantle, P. G., Thomas, A. J., et al. (1980). Actions of tremorgenic fungal toxins on neurotransmitter release. J. Neurochem. 34, 33-42. doi: 10.1111/j.1471-4159. 1980.tb04618.x

O’Brien, A. J., Terala, D., Orie, N. N., Davies, N. A., Zolfaghari, P., Singer, M., et al. (2011). BK large conductance $\mathrm{Ca}^{2+}$-activated $\mathrm{K}^{+}$cannel-deficient mice are not resistant to hypotension and display reduced survival benefit following polymicrobial sepsis. Shock 35, 485-491. doi: 10.1097/SHK. 0b013e31820860f5

Ottolia, M., and Toro, L. (1994). Potentiation of large conductance KCa channels by niflumic, flufenamic, and mefenamic acids. Biophys. J. 67, 2272-2279. doi: 10.1016/S0006-3495(94)80712-X

Pabbidi, M. R., and Roman, R. J. (2017). Elevated $\mathrm{K}^{+}$channel activity opposes vasoconstrictor response to serotonin in cerebral arteries of the fawn hooded hypertensive rat. Physiol. Genomics 49, 27-36. doi: 10.1152/ physiolgenomics.00072.2016

Pallotta, B. S., Magleby, K. L., and Barrett, J. N. (1981). Single channel recordings of $\mathrm{Ca}^{2+}$-activated $\mathrm{K}^{+}$currents in rat muscle cell culture. Nature 293, 471-474. doi: 10.1038/293471a0

Pantazis, A., Kohanteb, A. P., and Olcese, R. (2010). Relative motion of transmembrane segments S0 and S4 during voltage sensor activation in the human BK(Ca) channel. J. Gen. Physiol. 136, 645-657. doi: 10.1085/ jgp.201010503

Pantazis, A., and Olcese, R. (2012). Relative transmembrane segment rearrangements during BK channel activation resolved by structurally assigned fluorophore-quencher pairing. J. Gen. Physiol. 140, 207-218. doi: 10.1085/ jgp.201210807

Panyi, G., Possani, L. D., Rodríguez de la Vega, R. C., Gáspár, R., and Varga, Z. (2006). $\mathrm{K}^{+}$channel blockers: novel tools to inhibit $\mathrm{T}$ cell activation leading to specific immunosuppression. Curr. Pharm. Des. 12, 2199-2220. doi: $10.2174 / 138161206777585120$

Park, J. K., Kim, Y. C., Sim, J. H., Choi, M. Y., Choi, W., Hwang, K. K., et al. (2007). Regulation of membrane excitability by intracellular $\mathrm{pH}$ ( $\mathrm{pHi}$ ) changers through $\mathrm{Ca}^{2+}$-activated $\mathrm{K}^{+}$current (BK channel) in single smooth muscle cells from rabbit basilar artery. Pflugers Arch. 454, 307-319. doi: 10.1007/ s00424-007-0204-8

Pau, V. P., Smith, F. J., Taylor, A. B., Parfenova, L. V., Samakai, E., Callaghan, M. M., et al. (2011). Structure and function of multiple $\mathrm{Ca}^{2+}$-binding sites in a $\mathrm{K}^{+}$ channel regulator of $\mathrm{K}^{+}$conductance (RCK) domain. Proc. Natl. Acad. Sci. U. S. A. 108, 17684-17689. doi: 10.1073/pnas.1107229108

Peng, W., Hoidal, J. R., and Farrukh, I. S. (1996). Regulation of Ca(2+)activated $\mathrm{K}^{+}$channels in pulmonary vascular smooth muscle cells: role of nitric oxide. J. Appl. Physiol. 81, 1264-1272. doi: 10.1152/jappl. 1996.81.3.1264

Pérez, G. J., Bonev, A. D., Patlak, J. B., and Nelson, M. T. (1999). Functional coupling of ryanodine receptors to KCa channels in smooth muscle cells from rat cerebral arteries. J. Gen. Physiol. 113, 229-238. doi: 10.1085/ jgp.113.2.229

Porter, V. A., Bonev, A. D., Knot, H. J., Heppner, T. J., Stevenson, A. S., Kleppisch, T., et al. (1998). Frequency modulation of $\mathrm{Ca}^{2+}$ sparks is involved in regulation of arterial diameter by cyclic nucleotides. Am. J. Phys. 274, C1346-C1355. doi: 10.1152/ajpcell.1998.274.5.C1346

Raffaeli, G., Saviane, C., Mohajerani, M. H., Pedarzani, P., and Cherubini, E. (2004). BK potassium channels control transmitter release at CA3-CA3 synapses in the rabbit hippocampus. J. Physiol. 557, 147-157. doi: 10.1113/ jphysiol.2004.062661

Raingo, J., Rebolledo, A., Grassi de Gende, A. O., Sanz, N., Tommasi, J., and Milesi, V. (2005). pH effects on high conductance $\mathrm{Ca}^{2+}$-activated $\mathrm{K}^{+}$channels $(\mathrm{BK}(\mathrm{Ca}))$ in human internal mammary artery smooth muscle cells. Life Sci. 77, 1993-2003. doi: 10.1016/j.lfs.2005.03.015

Revermann, M., Neofitidou, S., Kirschning, T., Schloss, M., Brandes, R. P., and Hofstetter, C. (2014). Inhalation of the BK(Ca)-opener NS1619 attenuates right ventricular pressure and improves oxygenation in the rat monocrotaline model of pulmonary hypertension. PLoS One 9:e86636. doi: 10.1371/journal. pone.0086636

Robertson, B. E., Schubert, R., Hescheler, J., and Nelson, M. T. (1993). cGMPdependent protein kinase activates $\mathrm{Ca}$-activated $\mathrm{K}$ channels in cerebral artery smooth muscle cells. Am. J. Phys. 265, C299-C303. doi: 10.1152/ ajpcell.1993.265.1.C299

Robitaille, R., and Charlton, M. P. (1992). Presynaptic calcium signals and transmitter release are modulated by calcium-activated potassium channels. J. Neurosci. 12, 297-305. doi: 10.1523/JNEUROSCI.12-01-00297

Roy, S., Morayo Akande, A., Large, R. J., Webb, T. I., Camarasu, C., Sergeant, G. P., et al. (2012). Structure-activity relationships of a novel group of large-conductance $\mathrm{Ca}(2+)$-activated $\mathrm{K}(+)(\mathrm{BK})$ channel modulators: the GoSlo-SR family. ChemMedChem 7, 1763-1769. doi: 10.1002/cmdc 201200321

Sade, H., Muraki, K., Ohya, S., Hatano, N., and Imaizumi, Y. (2006). Activation of large-conductance, $\mathrm{Ca}^{2+}$-activated $\mathrm{K}^{+}$channels by cannabinoids. Am. J. Physiol. Cell Physiol. 290, C77-C86. doi: 10.1152/ajpcell.00482.2004

Sanchez, M., and McManus, O. B. (1996). Paxilline inhibition of the alphasubunit of the high-conductance calcium-activated potassium channel. Neuropharmacology 35, 963-968. doi: 10.1016/0028-3908(96)00137-2

Schubert, R., Krien, U., and Gagov, H. (2001). Protons inhibit the BK(Ca) channel of rat small artery smooth muscle cells. J. Vasc. Res. 38, 30-38. doi: $10.1159 / 000051027$

Schubert, R., and Nelson, M. T. (2001). Protein kinases: tuners of the BKCa channel in smooth muscle. Trends Pharmacol. Sci. 22, 505-512. doi: 10.1016/ s0165-6147(00)01775-2

Schubert, R., Noack, T., and Serebryakov, V. N. (1999). Protein kinase C reduces the KCa current of rat tail artery smooth muscle cells. Am. J. Phys. 276, C648-C658. doi: 10.1152/ajpcell.1999.276.3.C648

Seoh, S. A., Sigg, D., Papazian, D. M., and Bezanilla, F. (1996). Voltage-sensing residues in the S2 and S4 segments of the Shaker $\mathrm{K}^{+}$channel. Neuron 16, 1159-1167. doi: 10.1016/s0896-6273(00)80142-7

Shi, J., and Cui, J. (2001). Intracellular $\mathrm{Mg}(2+)$ enhances the function of BKtype $\mathrm{Ca}(2+)$-activated $\mathrm{K}(+)$ channels. J. Gen. Physiol. 118, 589-606. doi: 10.1085/jgp.118.5.589

Shi, J., Krishnamoorthy, G., Yang, Y., Hu, L., Chaturvedi, N., Harilal, D., et al. (2002). Mechanism of magnesium activation of calcium-activated potassium channels. Nature 418, 876-880. doi: 10.1038/nature00941

Shipston, M. J. (2001). Alternative splicing of potassium channels: a dynamic switch of cellular excitability. Trends Cell Biol. 11, 353-358. doi: 10.1016/ s0962-8924(01)02068-2

Shipston, M. J., and Tian, L. (2016). Posttranscriptional and posttranslational regulation of BK channels. Int. Rev. Neurobiol. 128, 91-126. doi: 10.1016/ bs.irn.2016.02.012

Singh, H., Stefani, E., and Toro, L. (2012). Intracellular BK(Ca) (iBK(Ca)) channels. J. Physiol. 590, 5937-5947. doi: 10.1113/jphysiol.2011.215533

Solaro, C. R., Prakriya, M., Ding, J. P., and Lingle, C. J. (1995). Inactivating and noninactivating $\mathrm{Ca}(2+)$ - and voltage-dependent $\mathrm{K}^{+}$current in rat adrenal chromaffin cells. J. Neurosci. 15, 6110-6123. doi: 10.1523/ JNEUROSCI.15-09-06110.1995

Strøbaek, D., Christophersen, P., Dissing, S., and Olesen, S. P. (1996a). ATP activates $\mathrm{K}$ and $\mathrm{Cl}$ channels via purinoceptor-mediated release of $\mathrm{Ca}^{2+}$ in human coronary artery smooth muscle. Am. J. Phys. 271, C1463-C14671. doi: 10.1152/ajpcell.1996.271.5.C1463

Strøbaek, D., Christophersen, P., Holm, N. R., Moldt, P., Ahring, P. K., Johansen, T. E., et al. (1996b). Modulation of the $\mathrm{Ca}(2+)$-dependent $\mathrm{K}^{+}$ channel, hslo, by the substituted diphenylurea NS 1608, paxilline and internal $\mathrm{Ca}^{2+}$. Neuropharmacology 35, 903-914. doi: 10.1016/00283908(96)00096-2

Sweet, T. B., and Cox, D. H. (2009). Measuring the influence of the BKCa \{beta\}1 subunit on $\mathrm{Ca}^{2+}$ binding to the BKCa channel. J. Gen. Physiol. 133, 139-150. doi: 10.1085/jgp.200810129

Taguchi, K., Kaneko, K., and Kubo, T. (2000). Protein kinase C modulates $\mathrm{Ca}^{2+}$-activated $\mathrm{K}^{+}$channels in cultured rat mesenteric artery smooth muscle cells. Biol. Pharm. Bull. 23, 1450-1454. doi: 10.1248/bpb.23.1450

Tanaka, M., Sasaki, Y., Kimura, Y., Fukui, T., Hamada, K., and Ukai, Y. (2003). A novel pyrrole derivative, NS-8, suppresses the rat micturition reflex by inhibiting afferent pelvic nerve activity. BJU Int. 92, 1031-1036. doi: 10.1111/j. 1464-410x.2003.04512.x 
Tanaka, Y., Yamaki, F., Koike, K., and Toro, L. (2004). New insights into the intracellular mechanisms by which PGI2 analogues elicit vascular relaxation: cyclic AMP-independent, Gs-protein mediated-activation of MaxiK channel. Curr. Med. Chem. Cardiovasc. Hematol. Agents 2, 257-265. doi: 10.2174/ 1568016043356273

Tang, X. D., Xu, R., Reynolds, M. F., Garcia, M. L., Heinemann, S. H., and Hoshi, T. (2003). Haem can bind to and inhibit mammalian calcium-dependent Slo1 BK channels. Nature 425, 531-535. doi: 10.1038/nature02003

Tang, Q. Y., Zhang, Z., Meng, X. Y., Cui, M., and Logothetis, D. E. (2014). Structural determinants of phosphatidylinositol 4,5-bisphosphate (PIP2) regulation of BK channel activity through the RCK1 $\mathrm{Ca}^{2+}$ coordination site. J. Biol. Chem. 289, 18860-18872. doi: 10.1074/jbc.M113.538033

Tao, X., Hite, R. K., and MacKinnon, R. (2017). Cryo-EM structure of the open high-conductance $\mathrm{Ca}^{2+}$-activated $\mathrm{K}^{+}$channel. Nature 541, 46-51. doi: 10.1038/nature20608

Tao, X., Lin, M. T., Thorington, G. U., Wilson, S. M., Longo, L. D., and Hessinger, D. A. (2015). Long-term hypoxia increases calcium affinity of BK channels in ovine fetal and adult cerebral artery smooth muscle. Am. J. Physiol. Heart Circ. Physiol. 308, H707-H722. doi: 10.1152/ ajpheart.00564.2014

Thuringer, D., and Findlay, I. (1997). Contrasting effects of intracellular redox couples on the regulation of maxi-K channels in isolated myocytes from rabbit pulmonary artery. J. Physiol. 500, 583-592. doi: 10.1113/jphysiol.1997. sp022044

Tian, L., Coghill, L. S., McClafferty, H., MacDonald, S. H., Antoni, F. A., Ruth, P., et al. (2004). Distinct stoichiometry of BKCa channel tetramer phosphorylation specifies channel activation and inhibition by cAMP-dependent protein kinase. Proc. Natl. Acad. Sci. U. S. A. 101, 11897-11902. doi: 10.1073/ pnas.0402590101

Tian, L., Duncan, R. R., Hammond, M. S., Coghill, L. S., Wen, H., Rusinova, R., et al. (2001). Alternative splicing switches potassium channel sensitivity to protein phosphorylation. J. Biol. Chem. 276, 7717-7720. doi: 10.1074/jbc. C000741200

Tian, L., Jeffries, O., McClafferty, H., Molyvdas, A., Rowe, I. C., Saleem, F., et al. (2008). Palmitoylation gates phosphorylation-dependent regulation of BK potassium channels. Proc. Natl. Acad. Sci. U. S. A. 105, 21006-21011. doi: $10.1073 /$ pnas.0806700106

Tian, Y., Ullrich, F., Xu, R., Heinemann, S. H., Hou, S., and Hoshi, T. (2015). Two distinct effects of PIP2 underlie auxiliary subunit-dependent modulation of Slo1 BK channels. J. Gen. Physiol. 145, 331-343. doi: 10.1085/jgp.201511363

Torres, Y. P., Granados, S. T., and Latorre, R. (2014). Pharmacological consequences of the coexpression of BK channel $\alpha$ and auxiliary $\beta$ subunits. Front. Physiol. 5:383. doi: $10.3389 /$ fphys.2014.00383

Trimmer, J. S. (2015). Subcellular localization of $\mathrm{K}^{+}$channels in mammalian brain neurons: remarkable precision in the midst of extraordinary complexity. Neuron 85, 238-256. doi: 10.1016/j.neuron.2014.12.042

Tseng-Crank, J., Foster, C. D., Krause, J. D., Mertz, R., Godinot, N., DiChiara, T. J., et al. (1994). Cloning, expression, and distribution of functionally distinct $\mathrm{Ca}(2+)$-activated $\mathrm{K}^{+}$channel isoforms from human brain. Neuron 13, 1315-1330. doi: 10.1016/0896-6273(94)90418-9

Vaithianathan, T., Bukiya, A., Liu, J., Liu, P., Asuncion-Chin, M., Fan, Z., et al. (2008). Direct regulation of BK channels by phosphatidylinositol 4,5-bisphosphate as a novel signaling pathway. J. Gen. Physiol. 132, 13-28. doi: 10.1085/jgp.200709913

Wallner, M., Meera, P., and Toro, L. (1996). Determinant for beta-subunit regulation in high-conductance voltage-activated and $\mathrm{Ca}(2+)$-sensitive $\mathrm{K}^{+}$ channels: an additional transmembrane region at the $\mathrm{N}$ terminus. Proc. Natl. Acad. Sci. U. S. A. 93, 14922-14927. doi: 10.1073/pnas.93. 25.14922

Wang, Z. W. (2008). Regulation of synaptic transmission by presynaptic CaMKII and BK channels. Mol. Neurobiol. 38, 153-166. doi: 10.1007/s12035-0088039-7

Wang, R. X., Chai, Q., Lu, T., and Lee, H. C. (2011). Activation of vascular BK channels by docosahexaenoic acid is dependent on cytochrome P450 epoxygenase activity. Cardiovasc. Res. 90, 344-352. doi: 10.1093/cvr/ cvq411

Wang, L., and Sigworth, F. J. (2009). Cryo-EM structure of the BK potassium channel in a lipid membrane. Nature 461, 292-295. doi: 10.1038/nature08291
Wellman, G. C., and Nelson, M. T. (2003). Signaling between SR and plasmalemma in smooth muscle: sparks and the activation of $\mathrm{Ca}^{2+}$-sensitive ion channels. Cell Calcium 34, 211-229. doi: 10.1016/s0143-4160(03)00124-6

Wiecha, J., Schläger, B., Voisard, R., Hannekum, A., Mattfeldt, T., and Hombach, V. (1997). $\mathrm{Ca}(2+)$-activated $\mathrm{K}^{+}$channels in human smooth muscle cells of coronary atherosclerotic plaques and coronary media segments. Basic Res. Cardiol. 92, 233-239. doi: 10.1007/BF00788518

Williams, S. E., Brazier, S. P., Baban, N., Telezhkin, V., Müller, C. T., Riccardi, D., et al. (2008). A structural motif in the C-terminal tail of slo1 confers carbon monoxide sensitivity to human BK Ca channels. Pflugers Arch. 456, 561-572. doi: 10.1007/s00424-007-0439-4

Wong, B. S. (1989). Quinidine blockade of calcium-activated potassium channels in dissociated gastric smooth muscle cells. Pflugers Arch. 414, 416-422. doi: 10.1007/BF00585051

Wu, S. N., Li, H. F., Jan, C. R., and Shen, A. Y. (1999). Inhibition of $\mathrm{Ca}^{2+}$ activated $\mathrm{K}^{+}$current by clotrimazole in rat anterior pituitary $\mathrm{GH} 3$ cells. Neuropharmacology 38, 979-989. doi: 10.1016/s0028-3908(99)00027-1

Xia, X. M., Fakler, B., Rivard, A., Wayman, G., Johnson-Pais, T., Keen, J. E., et al. (1998). Mechanism of calcium gating in small-conductance calciumactivated potassium channels. Nature 395, 503-507.

Xia, X. M., Zeng, X., and Lingle, C. J. (2002). Multiple regulatory sites in large-conductance calcium-activated potassium channels. Nature 418, 880-884. doi: $10.1038 /$ nature00956

Xu, W., Liu, Y., Wang, S., McDonald, T., Van Eyk, J. E., Sidor, A., et al. (2002). Cytoprotective role of $\mathrm{Ca}^{2+}$ - activated $\mathrm{K}^{+}$channels in the cardiac inner mitochondrial membrane. Science 298, 1029-1033. doi: 10.1126/science. 1074360

Yan, J., and Aldrich, R. W. (2010). LRRC26 auxiliary protein allows BK channel activation at resting voltage without calcium. Nature 466, 513-516. doi: $10.1038 /$ nature09162

Yan, J., and Aldrich, R. W. (2012). BK potassium channel modulation by leucine-rich repeat-containing proteins. Proc. Natl. Acad. Sci. U. S. A. 109, 7917-7922. doi: 10.1073/pnas.1205435109

Yang, C., Gonzalez-Perez, V., Mukaibo, T., Melvin, J. E., Xia, X. M., and Lingle, C. J. (2017). Knockout of the LRRC26 subunit reveals a primary role of LRRC26-containing BK channels in secretory epithelial cells. Proc. Natl. Acad. Sci. U. S. A. 114, E3739-E3747. doi: 10.1073/pnas. 1703081114

Yang, H., Shi, J., Zhang, G., Yang, J., Delaloye, K., and Cui, J. (2008). Activation of Slo1 BK channels by $\mathrm{Mg}^{2+}$ coordinated between the voltage sensor and RCK1 domains. Nat. Struct. Mol. Biol. 15, 1152-1159. doi: 10.1038/ nsmb.1507

Yuan, P., Leonetti, M. D., Pico, A. R., Hsiung, Y., and McKinnon, R. (2010). Structure of the human $\mathrm{BK}$ channel $\mathrm{Ca}^{2+}$-activation apparatus at $3.0 \mathrm{~A}$ resolution. Science 329, 182-186. doi: 10.1126/science.1190414

Zamoyski, V. L., Serebryakov, V. N., and Schubert, R. (1989). Activation and blocking effects of divalent cations on the calcium-dependent potassium channel of high conductance. Biomed. Biochim. Acta 48, S388-S392.

Zarei, M. M., Eghbali, M., Alioua, A., Song, M., Knaus, H. G., Stefani, E., et al. (2004). An endoplasmic reticulum trafficking signal prevents surface expression of a voltage- and $\mathrm{Ca}^{2+}$-activated $\mathrm{K}^{+}$channel splice variant. Proc. Natl. Acad. Sci. U. S. A. 101, 10072-10077. doi: 10.1073/pnas. 0302919101

Zeng, X. H., Xia, X. M., and Lingle, C. J. (2005). Divalent cation sensitivity of BK channel activation supports the existence of three distinct binding sites. J. Gen. Physiol. 125, 273-286. doi: 10.1085/jgp.200409239

Zhang, Z., Li, M., Lu, R., Alioua, A., Stefani, E., and Toro, L. (2014). The angiotensin II type 1 receptor (AT1R) closely interacts with large conductance voltage- and $\mathrm{Ca}^{2+}$-activated $\mathrm{K}^{+}(\mathrm{BK})$ channels and inhibits their activity independent of G-protein activation. J. Biol. Chem. 289, 25678-25689. doi: 10.1074/jbc.M114.595603

Zhang, X., Puil, E., and Mathers, D. A. (1995). Effects of intracellular Mg2+ on the properties of large-conductance, $\mathrm{Ca}(2+)$-dependent $\mathrm{K}^{+}$channels in rat cerebrovascular smooth muscle cells. J. Cereb. Blood Flow Metab. 15, 1066-1074. doi: 10.1038/jcbfm.1995.133

Zhang, X., Solaro, C. R., and Lingle, C. J. (2001). Allosteric regulation of BK channel gating by $\mathrm{Ca}(2+)$ and $\mathrm{Mg}(2+)$ through a nonselective, low affinity divalent cation site. J. Gen. Physiol. 118, 607-636. doi: 10.1085/jgp.118. 5.607 
Zhang, J., and Yan, J. (2014). Regulation of BK channels by auxiliary $\gamma$ subunits. Front. Physiol. 5:401. doi: 10.3389/fphys.2014.00401

Zhou, X. B., Wang, G. X., Huneke, B., Wieland, T., and Korth, M. (2000). Pregnancy switches adrenergic signal transduction in rat and human uterine myocytes as probed by BKCa channel activity. J. Physiol. 524, 339-352. doi: 10.1111/j.1469-7793.2000.t01-1-00339.x

Zhou, Y., Xia, X. M., and Lingle, C. J. (2020). The functionally relevant site for paxilline inhibition of BK channels. Proc. Natl. Acad. Sci. U. S. A. 117, 1021-1026. doi: 10.1073/pnas.1912623117

Conflict of Interest: The authors declare that the research was conducted in the absence of any commercial or financial relationships that could be construed as a potential conflict of interest.
Publisher's Note: All claims expressed in this article are solely those of the authors and do not necessarily represent those of their affiliated organizations, or those of the publisher, the editors and the reviewers. Any product that may be evaluated in this article, or claim that may be made by its manufacturer, is not guaranteed or endorsed by the publisher.

Copyright (ㅇ) 2021 Sancho and Kyle. This is an open-access article distributed under the terms of the Creative Commons Attribution License (CC BY). The use, distribution or reproduction in other forums is permitted, provided the original author(s) and the copyright owner(s) are credited and that the original publication in this journal is cited, in accordance with accepted academic practice. No use, distribution or reproduction is permitted which does not comply with these terms. 